\title{
Transcriptional regulation of P63 on the apoptosis of male germ cells and three stages of spermatogenesis in mice
}

Hong Wang ${ }^{1}$, Qingqing Yuan ${ }^{1}$, Minghui Niu', Wenhui Zhang ${ }^{1}$, Liping Wen ${ }^{1}$, Hongyong Fu', Fan Zhou ${ }^{1}$ and Zuping $\mathrm{He}^{1,2,3,4}$

\begin{abstract}
Infertility affects $10-15 \%$ of couples worldwide, and male factors account for $50 \%$. Spermatogenesis is precisely regulated by genetic factors, and the mutations of genes result in abnormal spermatogenesis and eventual male infertility. The aim of this study was to explore the role and transcriptional regulation of P63 in the apoptosis and mouse spermatogenesis. P63 protein was decreased in male germ cells of $\mathrm{P} 63^{(+/-)}$mice compared with wild-type mice. There was no obvious difference in testis weight, sperm motility, and fecundity between $\mathrm{P} 63^{(+/-)}$and wild-type mice. However, abnormal germ cells were frequently observed in $\mathrm{P} 63^{(+/-)}$mice at 2 months old. Notably, apoptotic male germ cells and the percentage of abnormal sperm were significantly enhanced in $\mathrm{P}_{6} 3^{(+/-)}$mice compared to wild-type mice. Spermatogonia, pachytene spermatocytes and round spermatids were isolated from $\mathrm{P} 63^{(+/-)}$and wild-type mice using STA-PUT velocity sedimentation, and they were identified phenotypically with high purities. RNA sequencing demonstrated distinct transcription profiles in spermatogonia, pachytene spermatocytes, and round spermatids between $\mathrm{P} 63^{(+/-)}$mice and wild-type mice. In total, there were 645 differentially expressed genes (DEGs) in spermatogonia, 106 DEGs in pachytene spermatocytes, and 1152 in round spermatids between P63 ${ }^{(+/-)}$mice and wild-type mice. Real time PCR verified a number of DEGs identified by RNA sequencing. Gene ontology annotation and pathway analyzes further indicated that certain key genes, e.g., Ccnd2, Tgfa, Hes5, Ins/3, Kit, Lef1, and Jun were involved in apoptosis, while Dazl, Kit, Pld6, Cdkn2d, Stra8, and Ubr2 were associated with regulating spermatogenesis. Collectively, these results implicate that P63 mediates the apoptosis of male germ cells and regulates three stages of spermatogenesis transcriptionally. This study could provide novel targets for the diagnosis and treatment of male infertility.
\end{abstract}

\section{Introduction}

The $P 63$ gene, also known as Trp63 gene, encodes two isoforms, namely TAp63 and $\Delta N p 63$, and alternative splicing at the $\mathrm{C}$-terminus forms three different proteins, including $\alpha, \beta$ and $\gamma$ for both TAp63 and $\Delta$ Np63. It has

\footnotetext{
Correspondence: Zuping He (zupinghe@sjtu.edu.cn)

${ }^{1}$ State Key Laboratory of Oncogenes and Related Genes, Renji- Med X Clinical Stem Cell Research Center, Ren Ji Hospital, School of Medicine, Shanghai Jiao Tong University, Shanghai 200127, China

${ }^{2}$ Shanghai Institute of Andrology, Ren Ji Hospital, School of Medicine, Shanghai Jiao Tong University, 145 Shangdong Road, Shanghai 200001, China Full list of author information is available at the end of the article

Hong Wang, Qingqing Yuan, and Minghui Niu contributed equally to this work Edited by M. Agostini
}

been reported that P63 is expressed in various kinds of tissues, including heart, epidermis, urothelium, cervix, testis, kidney, thymus, and prostate in humans and mice ${ }^{1}$. TAp63 mainly induces cell cycle arrest and/or apoptosis, whereas $\Delta N p 63$ usually has an opposite effect on TAp $63^{1,2}$. The $\alpha$ isoform of TAp63 and $\Delta N p 63$ is the longest one, which specifically contains the Sterile A Motif (SAM) domain that is thought to be involved in certain biological processes, e.g., development, apoptosis, and differentiation $^{3,4}$. The $\beta$ and $\gamma$ isoforms of TAp63 and $\Delta N p 63$ have a transactivating activity, and conversely the $\alpha$ isoform changes were made. The images or other third party material in this article are included in the article's Creative Commons license, unless indicated otherwise in a credit line to the material. If
material is not included in the article's Creative Commons license and your intended use is not permitted by statutory regulation or exceeds the permitted use, you will need to obtain permission directly from the copyright holder. To view a copy of this license, visit http://creativecommons.org/licenses/by/4.0/. 
represses transactivating activity by the $\mathrm{C}$-terminal domain. It has been shown that TAp63 gene is present in adult mouse testis whereas $\Delta N p 63$ transcript is undetected in testis ${ }^{1}$. Nevertheless, other study has reported that $\Delta N p 63$ is expressed in the testis of mice from post-natal day 1 to day 7 and from 3 to 4 weeks old ${ }^{5}$. At the embryo stage, P63 has been shown to balance the numbers of male germ cells by controlling germ cell apoptosis ${ }^{6}$. However, it remains to examine the role and molecular mechanism of P63 in regulating male germ cell development in adult mice.

Infertility affects $10-15 \%$ of couples worldwide, and male factors account for $50 \%$. Spermatogenesis is a complex process that includes three main stages, namely the mitosis of spermatogonia, meiosis of spermatocytes, and spermiogenesis of spermatids. Spermatogenesis is precisely regulated by genetic factors, and the mutations of genes result in abnormal spermatogenesis and eventual male infertility. Since P63 homogeneous mutant mice die within several hours after birth due to maternal neglect and dehydra$\operatorname{tion}^{7,8}, \mathrm{P} 63^{(+/-)}$adult mice were thus utilized in this study to probe the function and transcriptional regulation of P63 in three stages of mammalian spermatogenesis. P63 mutation was generated by the $\mathrm{pTV} 12 \mathrm{E}(60)$ vector that was integrated into $p 63$ locus to produce a recombinant allele, namely $p 63^{\text {Brdm27 }}$. STA-PUT velocity sedimentation was used to effectively separate spermatogonia, pachytene spermatocytes and round spermatids from wild-type mice and $\mathrm{P}_{63}^{(+-)}$mice. We and peers have demonstrated that it is feasible to obtain various kinds of male germ cells with high purity and viability in humans and mice via STA-PUT velocity sedimentation ${ }^{9-11}$. STA-PUT approach can be effectively used to separate cells in terms of the unit gravity based upon cell size and mass via a linear BSA gradient and sedimentation velocity ${ }^{12-14}$. Compared with other techniques, e.g., fluorescence-activated cell sorting (FACS), magnetic-activated cell sorting (MACS) and elutriation, STA-PUT approach has several advantages in obtaining each specific cell type of male germ cells, including high purity and viability of these cells ${ }^{11}$. In this study, we have for the first time demonstrated that P63 mutation leads to the increases in apoptosis of male germ cells and abnormal sperm. Furthermore, we have unveiled a large scale of distinct transcription profiles in spermatogonia, pachytene spermatocytes, and round spermatids between $\mathrm{P} 63^{(+/-)}$ mice and wild-type mice. This study thus sheds a novel insight into the function and mechanisms of P63 in mediating the apoptosis of male germ cells and mammalian spermatogenesis and it offers novel targets for treating male infertility.

\section{Results}

\section{Genotype of the $\mathrm{P} 63^{(+/-)}$mice}

The genotype of the offspring of the $\mathrm{P} 63^{(+/-)}$male mice and wild-type (C57BL/6) female mice was identified using
PCR. We observed that the amplified genomic DNA fragments of $p 63^{\mathrm{Brdm} 2}$ were present in $\mathrm{P} 63^{(+/-)}$male mice but undetected in wild-type female mice (Fig. 1a). PCR showed that the level of $P 63$ gene was lower in $\mathrm{P}_{63}^{(+/-)}$ male mice than wild-type mice (Fig. 1b, c). We chose an antibody that specially recognized all P63 isoforms to
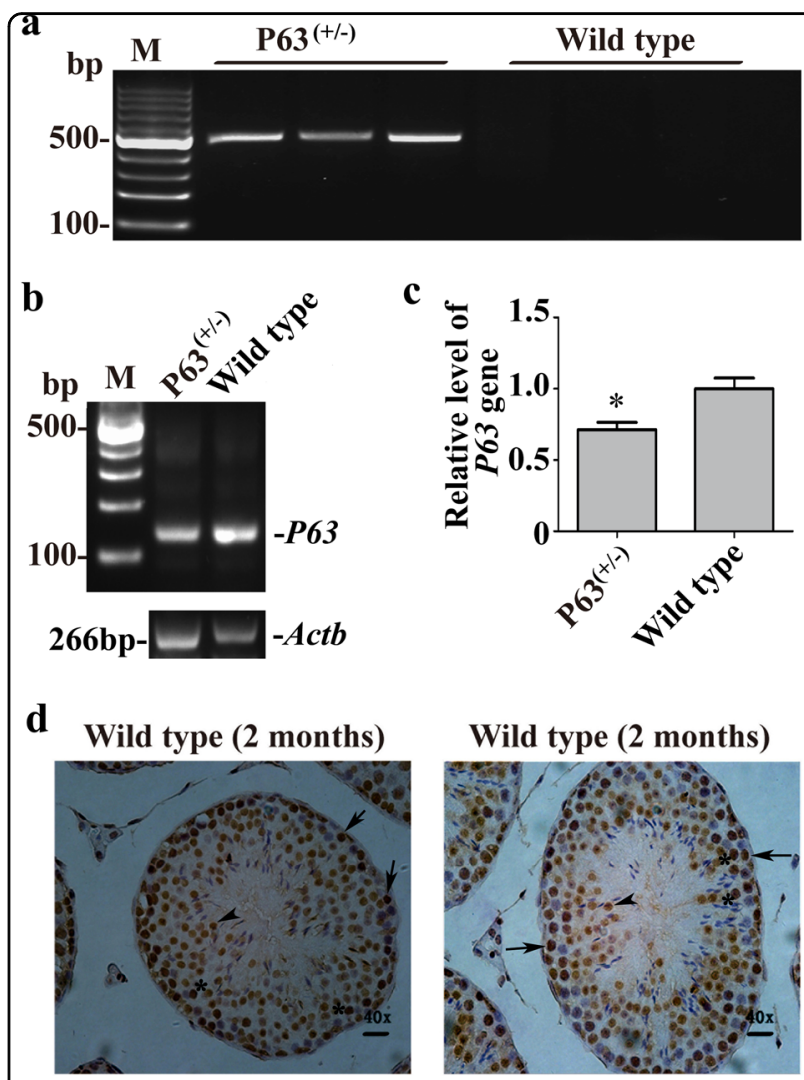

e

$\mathrm{P63}^{(+/-)}$(2 months)

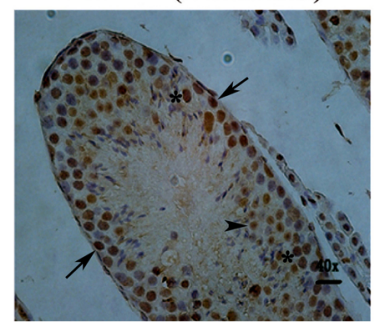

$\mathrm{P63}^{(+/-)}$(2 months)

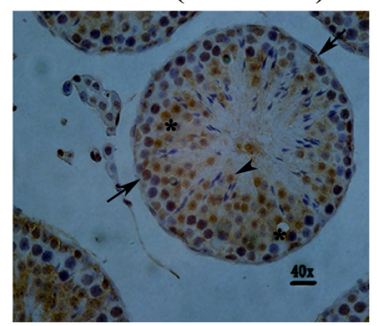

f
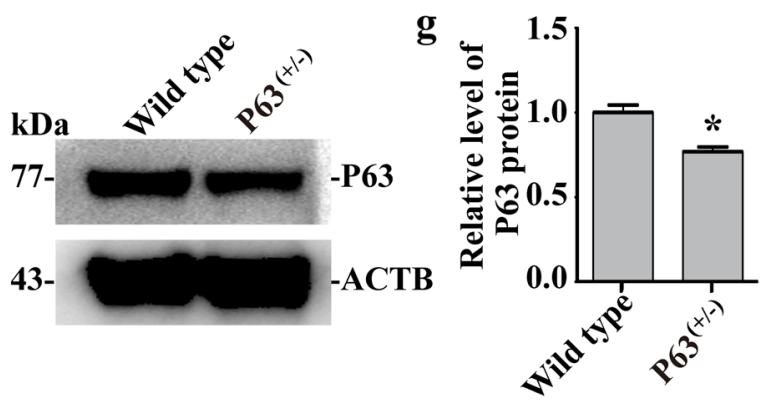

Fig. 1 (See legend on next page.) 
Fig. 1 Genotype and the expression of P63 protein in $\mathrm{P} 63^{(+/-)}$ mice and wild-type mice. PCR showed the DNA fragment of $p 63^{\mathrm{Brdm} 2}$ in $\mathrm{P} 63^{(+-)}$mice and wild-type mice a. PCR indicated the expression of $P 63$ gene in $P 63^{(+/-)}$male mice and wild-type mice $\mathbf{b}-\mathbf{c}$. Immunohistochemistry revealed the protein expression of P63 in the testis sections from wild-type mice $\mathbf{d}$ and $\mathrm{P} 63^{(+/-)}$mice $\mathbf{e}$. Scale bars in $\mathbf{d}-\mathbf{e}=20 \mu \mathrm{m}$. Western bolts demonstrated the protein expression of $\mathrm{P} 63$ in male germ cells of $\mathrm{P} 63^{(+/)}$mice and wild-type mice $\mathbf{f}$. ACTB served as a loading control of total proteins. The relative expression level of P63 in male germ cells of P $63^{(+/-)}$mice and wild-type mice after normalization to ACTB $\mathbf{g}$. ${ }^{*}$ indicated statistically significant differences $(p<0.05)$ between the $\mathrm{P} 63^{(+/-)}$mice and wild-type mice

locate P63 protein in mouse testes. Immunohistochemistry revealed that $\mathrm{P} 63$ protein was expressed in the nuclei of spermatogonia (arrows), spermatocytes (asterisks), and round spermatids (arrowheads) in wild-type male mice (Fig. 1d) and the $\mathrm{P} 63^{(+/-)}$male mice (Fig. 1e). Furthermore, western bolts demonstrated that the expression level of the P63 protein was decreased by $23.1 \% \pm 3.4 \%$ in male germ cells of the $\mathrm{P} 63^{(+/-)}$mice compared to wildtype mice (Fig. 1f, g). These results suggest that P63 mutation leads to the reduction of $\mathrm{P} 63$ protein in male mice.

\section{Phenotypic characteristics of the $\mathrm{P} 63^{(+/-)}$mice and wild-type mice}

We next evaluated the phenotypic characteristics of the $\mathrm{P} 63^{(+/-)}$mice and wild-type mice. There was no obvious difference in the size and weight of testes between the $\mathrm{P} 3^{(+/-)}$mice $(63.5 \pm 4.9 \mathrm{mg}, P=0.80, n=6)$ and the wild-type mice $(64.2 \pm 3.9 \mathrm{mg}, P=0.80, n=6)$ (Fig. $2 \mathrm{a}-\mathrm{c}$ ). However, $H \& E$ staining showed that abnormal and larger male germ cells (arrows) frequently existed in seminiferous tubules especially in the lumen of the $\mathrm{P} 63^{(+/-)}$mice (Fig. 2d, right panel), while normal male germ cells were found in the testes of wild-type mice (Fig. 2d, left panel). Meanwhile, we found atrophy (arrowheads) of seminiferous tubule epithelium in the $\mathrm{P} 63^{(+/-)}$mice (Fig. 2d, right panel). There was no significant difference in the fecundity $(6.6 \pm 2.4$ vs. $7.1 \pm 2.6, P=0.70, n=8)$ (Fig. $2 \mathrm{e}$ ), sperm motility $(59.0 \% \pm 13.2 \%$ vs. $61.0 \% \pm 12.1 \%, P=$ $0.86, n=3$ ) (Fig. 2f), or the percentages of progressive motility sperms $(45.0 \% \pm 15.0 \%$ vs. $47.7 \% \pm 12.7 \%, P=$ $0.83, n=3$ ) (Fig. $2 \mathrm{~g}$ ) between the $\mathrm{P} 63^{(+/-)}$mice and wildtype mice. The motility of sperm can be classified as nonmotile, non-progressive motile, and progressive motile. Non-motile and non-progressive motile spermatozoa lead to male infertility, whereas progressive motile spermatozoa have the potential of fecundity ${ }^{15}$. Furthermore, the
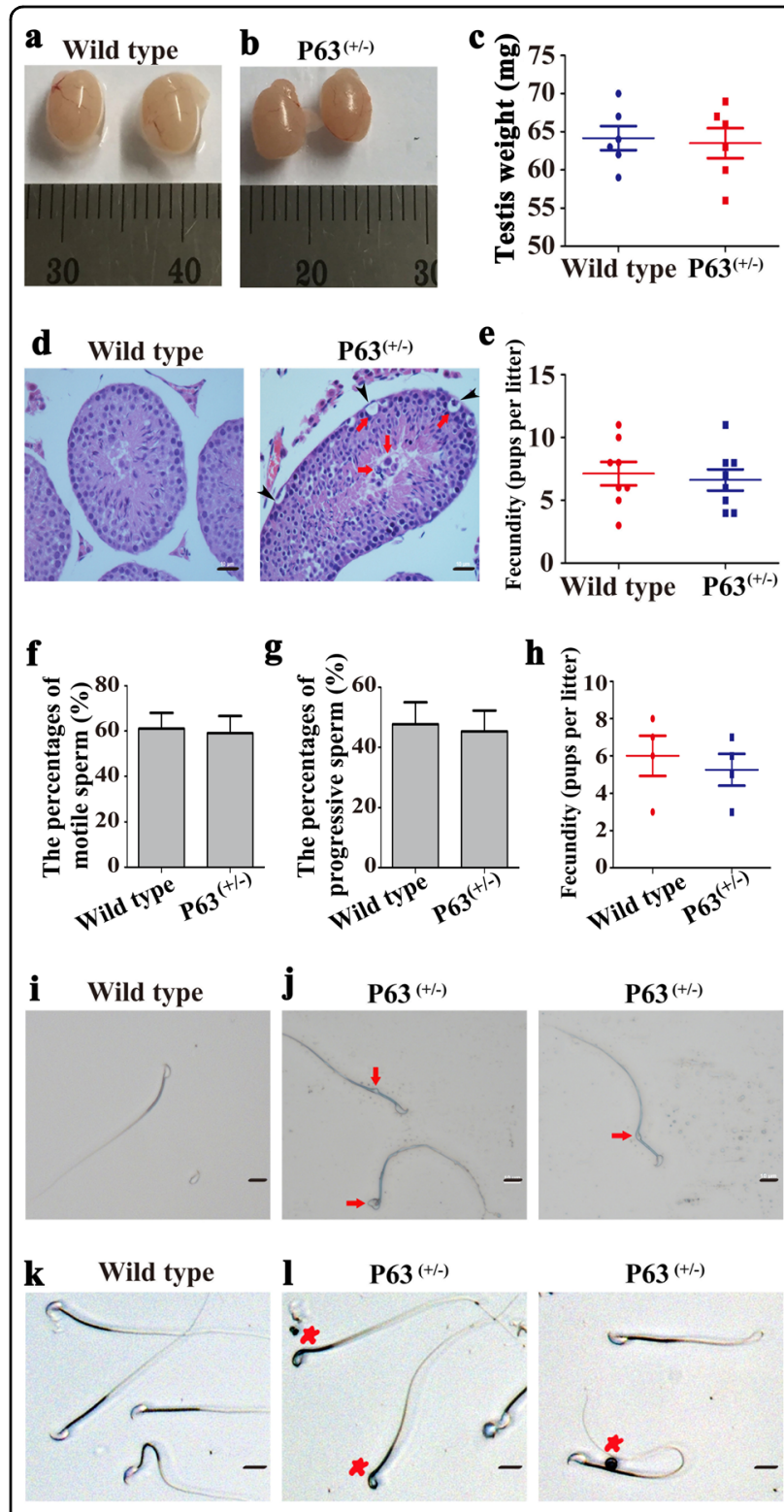

Fig. 2 The phenotypic characterization of the $\mathrm{P} 63^{(+/-)}$mice and wild-type mice. The images of testes from wild-type mice $\mathbf{a}$ and $\mathrm{P} 63^{(+/)}$mice $\mathbf{b}$ at 2 months old. The testis weight of wild-type mice and $\mathrm{P} 63^{(+/)}$mice at 2 months old $(n=6) \mathbf{c}$. H\&E staining of testis sections from wild-type mice (d, left panel) and $\mathrm{P} 63^{(+/)}$mice $(\mathbf{d}$, right panel) at 2 months old. Scale bar in $\mathbf{d}=20 \mu \mathrm{m}$. The numbers of pups per litter of wild-type mice and P63 $3^{(+/-)}$male mice at 2-8 months old crossed with wild-type female mice $\mathbf{e}$. The percentages of motile sperm $\mathbf{f}$ and progressive sperm $\mathbf{g}$ in wild-type mice and $\mathrm{P} 63^{(+/)}$mice at 2 months old. All data of motility measurements were presented from at least three independent experiments. The fecundity of $\mathrm{P} 63^{(+/-)}$ mice and wild-type mice at round 12 months $\mathbf{f}$. The morphology of sperm of wild-type mice $\mathbf{i}$ and $\mathrm{P} 63^{(+/-)}$mice $\mathbf{j}$ at 2 months old under a phase-contrast microscope. H\&E staining of sperm from wild-type mice $\mathbf{k}$ and $\mathrm{P} 63^{(+/-)}$mice $\mathbf{I}$ at 2 months old. Scale bars in $\mathbf{i}-\mathbf{I}=20 \mu \mathrm{m}$ 


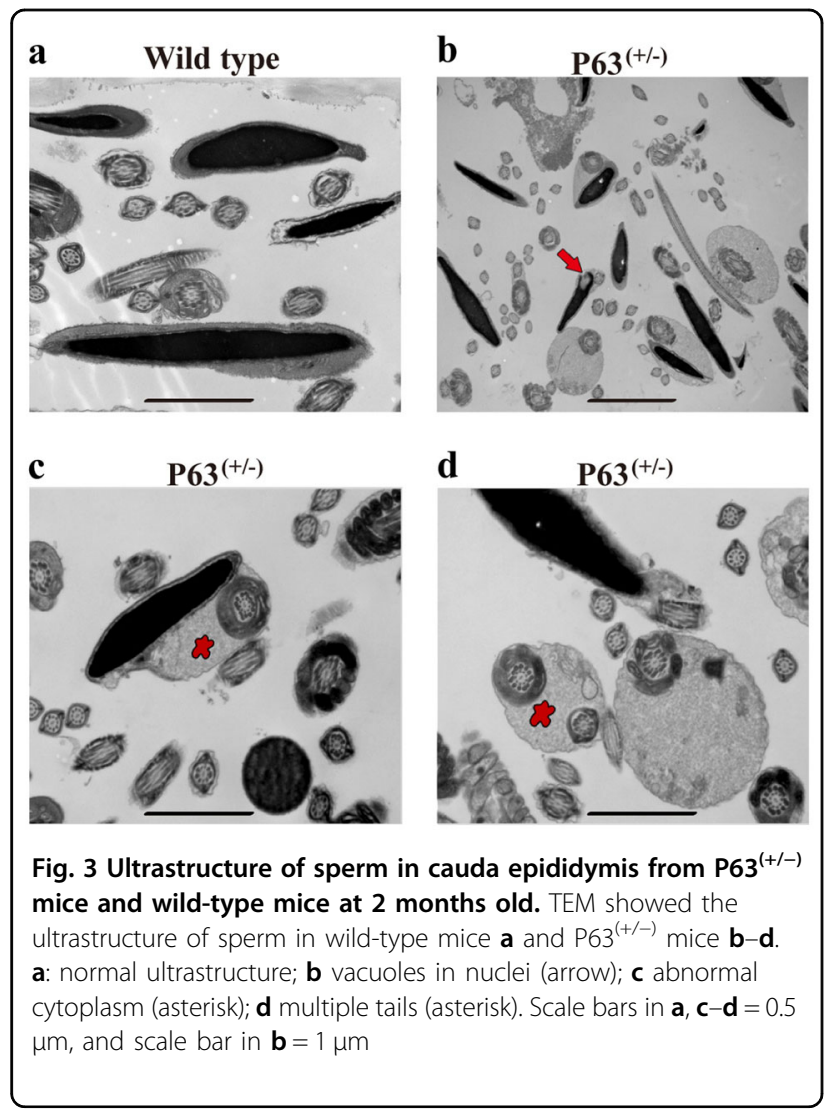

fecundity was reduced from $6.0 \pm 2.2(n=4)$ in wild-type mice to $5.3 \pm 1.7(n=4)$ in $\mathrm{P} 63^{(+/-)}$mice at round 12 months (Fig. 2h) in spite of no statistical difference between these two groups, since $\mathrm{P} 63^{(+/-)}$mice are heterozygous mutation rather than homozygous mutation. Notably, phase-contrast microscope and hematoxylineosin $(H \& E)$ staining demonstrated that there were a number of abnormal sperm, e.g., round-headed spermatozoa (asterisks), cytoplasmic droplet (arrows), and aberrant sperm tails $(20.8 \% \pm 4.3 \%)$ in the $\mathrm{P} 3^{(+/-)}$mice (Fig. 2j, l), while sperm with normal morphology were found in wild-type mice (Fig. 2i, k). Moreover, transmission electron microscopy (TEM) displayed that nucleus vacuoles (Fig. 3b, arrow), abnormal cytoplasm (Fig. 3c, asterisk), and multiple tails (Fig. 3d, asterisk) were seen in sperm of the $\mathrm{P} 63^{(+/-)}$mice $(27.3 \% \pm 3.6 \%)$ compared to wild-type mice $(9.8 \% \pm 3.3 \%)$ (Fig. 3a). Collectively, these data indicate that P63 mutation results in abnormalities in morphology and ultrastructure of sperm in mice.

\section{P63 mutation results in more apoptotic cells in mice}

Annexin V-FITC/propidium iodide (PI) staining and flow cytometry was used to compare the apoptosis of male germ cells in the $\mathrm{P} 63^{(+-)}$mice and the wild-type mice by two-step enzymatic digestion and the differential plating.
As shown in Fig. 4a-c, the percentage of the early apoptotic male germ cells was enhanced from $22.9 \% \pm 2.0 \%$ to $31.5 \% \pm 1.7 \%$ in $\mathrm{P} 63^{(+/-)}$mice compared with wild-type mice. In addition, the percentage of the late apoptotic male germ cells was increased from $3.0 \% \pm 0.4 \%$ to $7.1 \% \pm 1.6 \%$ in $\mathrm{P} 63^{(+/-)}$mice compared to wild-type mice (Fig. 4a, b, d). The results suggest that P63 mutation leads to more apoptotic cells in mice. TUNEL assay further revealed that the percentage of TUNEL-positive cells were increased from $2.3 \% \pm 0.5 \%$ to $4.1 \% \pm 0.5 \%$ in $\mathrm{P}_{6} 3^{(+/-)}$ mice (Fig. 4e) compared to wild-type mice (Fig. 4f). These results suggest that P63 mutation leads to more apoptosis in mouse testis in vivo.

\section{Isolation and identification of mouse spermatogonia,} pachytene spermatocytes, and round spermatids from the $\mathrm{P} 63^{(+/-)}$mice and wild-type mice

STA-PUT apparatus via the velocity sedimentation was used to isolate spermatogonia, pachytene spermatocytes, and round spermatids from $\mathrm{P} 63^{(+/-)}$mice and wild-type mice. The isolated cells were identified according to their morphological characteristics and phenotype using specific gene and protein markers for these cells. Mouse spermatogonia were collected by cell fractions $35-50$, and under the phase-contrast microscope, they were spherical in morphology with large and round nuclei and a diameter ranging from 10 to $12 \mu \mathrm{m}$ (Fig. $5 \mathrm{a}$, left panel). Pachytene spermatocytes were obtained by cell fractions $5-25$, and these cells had patchy condensed chromatin with the diameter ranging from 14 to $18 \mu \mathrm{m}$ (Fig. 5a, middle panel). Meanwhile, round spermatids were collected from 60 to 75, and they were smaller cells with round nuclei with a diameter ranging from 8 to $10 \mu \mathrm{m}$ (Fig. 5a, right panel). A number of gene markers for spermatogonia, pachytene spermatocytes, and round spermatids were chosen to assess the phenotype of the freshly isolated cells using RT-PCR. We found that the transcripts of Gpr125, Gfra1, Thy1, and Zbtb16 (also known as $P l z f$ ) were expressed in isolated spermatogonia (Fig. 5b), and Scp3, Crest, and Mlh1 mRNA was detected in isolated pachytene spermatocytes (Fig. 5c). Additionally, the transcription of Acr, Tnp1, and Prm1 was present in isolated round spermatids (Fig. 5d). The expression of the genes mentioned above in mouse testis served as positive controls, and RNA without RT (RT-) but with PCR was utilized as a negative control. In contrast, the transcripts of Scp3, Crest, Mlh1, Acr, Tnp1, and Prm1 were not detected in isolated spermatogonia (Supplemental Fig. 1a), and Gpr125, Gfra1, Zbtb16, Acr, Tnp1, and Prm1 were undetected in isolated pachytene spermatocytes (Supplemental Fig. 1b). The transcription of Gpr125, Gfra1, Zbtb16, Scp3, Crest, and Mlh1 was not detected in isolated round spermatids (Supplemental Fig. 1c). 

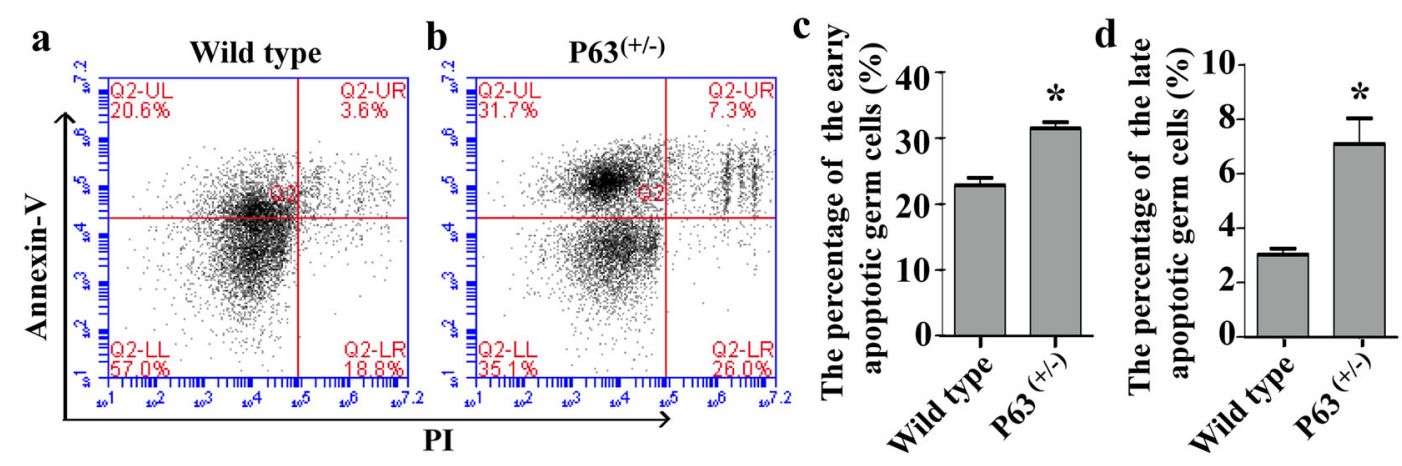

e

TUNEL

PI
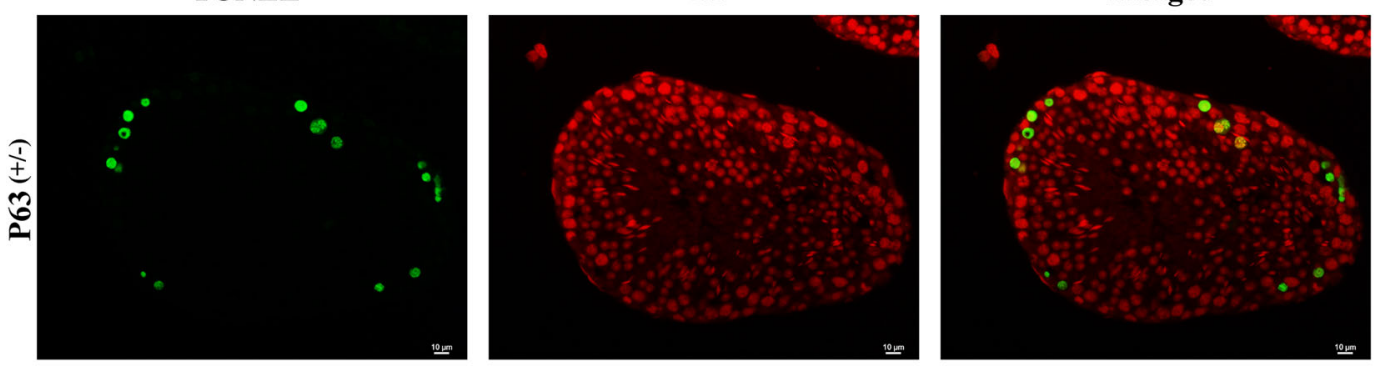

$\mathbf{f}$

TUNEL

PI
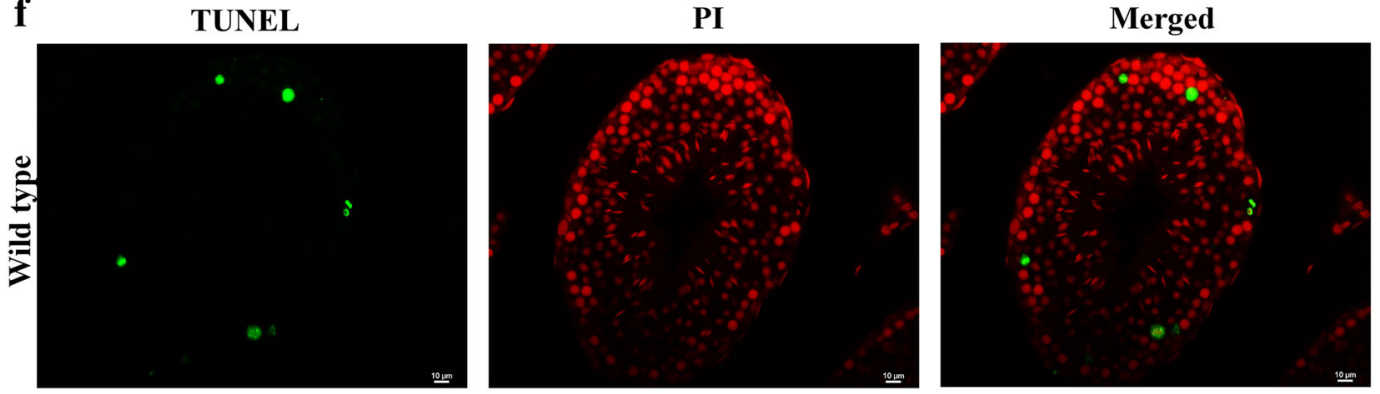

$\mathbf{g}$

PBS

PI
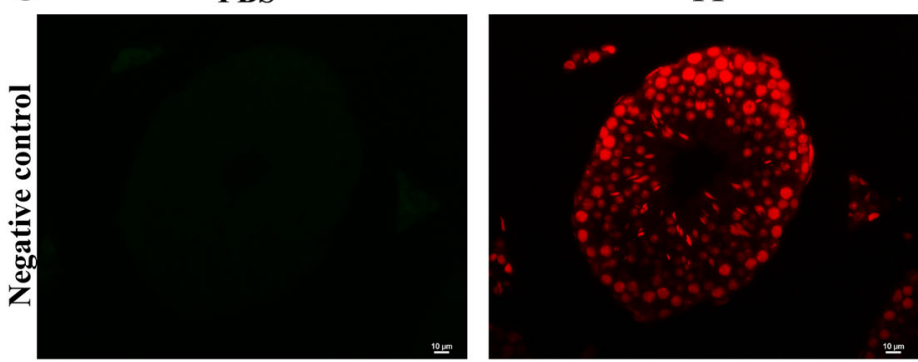

Merged

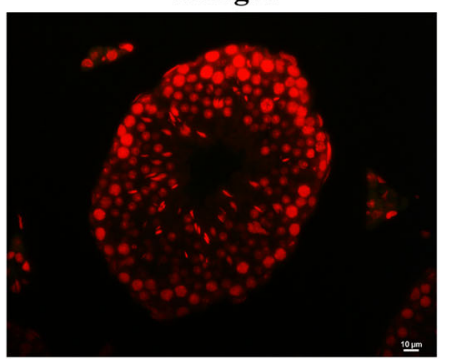

Fig. 4 The apoptosis in male germ cells of the $\mathrm{P}_{63^{(+/-)}}$mice and wild-type mice. The percentages of apoptotic male germ cells in wild-type mice $\mathbf{a}$ and $\mathrm{P} 63^{(+/)}$mice $\mathbf{b}$ at 2 months old. The percentages of early apoptosis $\mathbf{c}$ and late apoptosis $\mathbf{d}$ in male germ cells of wild-type mice and P63 ${ }^{(+/-)}$mice were calculated using Student's $t$-test. * indicated statistically significant differences $(p<0.05)$. TUNEL assay demonstrated the TUNELpositive cells (green fluorescence) in P6 $3^{(+/)}$mice $\mathbf{e}$ and wild-type mice $\mathbf{f}$. Replacement the TdT enzyme with PBS was used as the negative control $\mathbf{g}$. PI (red fluorescence) was used to label cell nuclei. Scale bars in $\mathbf{e}-\mathbf{g}=10 \mu \mathrm{m}$. The data in Fig. 4a-g were presented from three independent experiments

Furthermore, immunocytochemistry was performed to identify the purity of spermatogonia and round spermatids. As shown in Fig. 6, more than 90\% of isolated cells were positive for UCHL1 (Fig. 6a), GFRA1 (Fig. 6b),
THY1 (Fig. 6c), and GPR125 (Fig. 6d), markers for spermatogonia and $\mathrm{SSCs}^{16}$. In total, over $95 \%$ of haploid cells were stained positively for PRM1 (Fig. 6e) and PNA (Fig. 6f), hallmarks for round spermatids ${ }^{11}$. Meiosis spread 

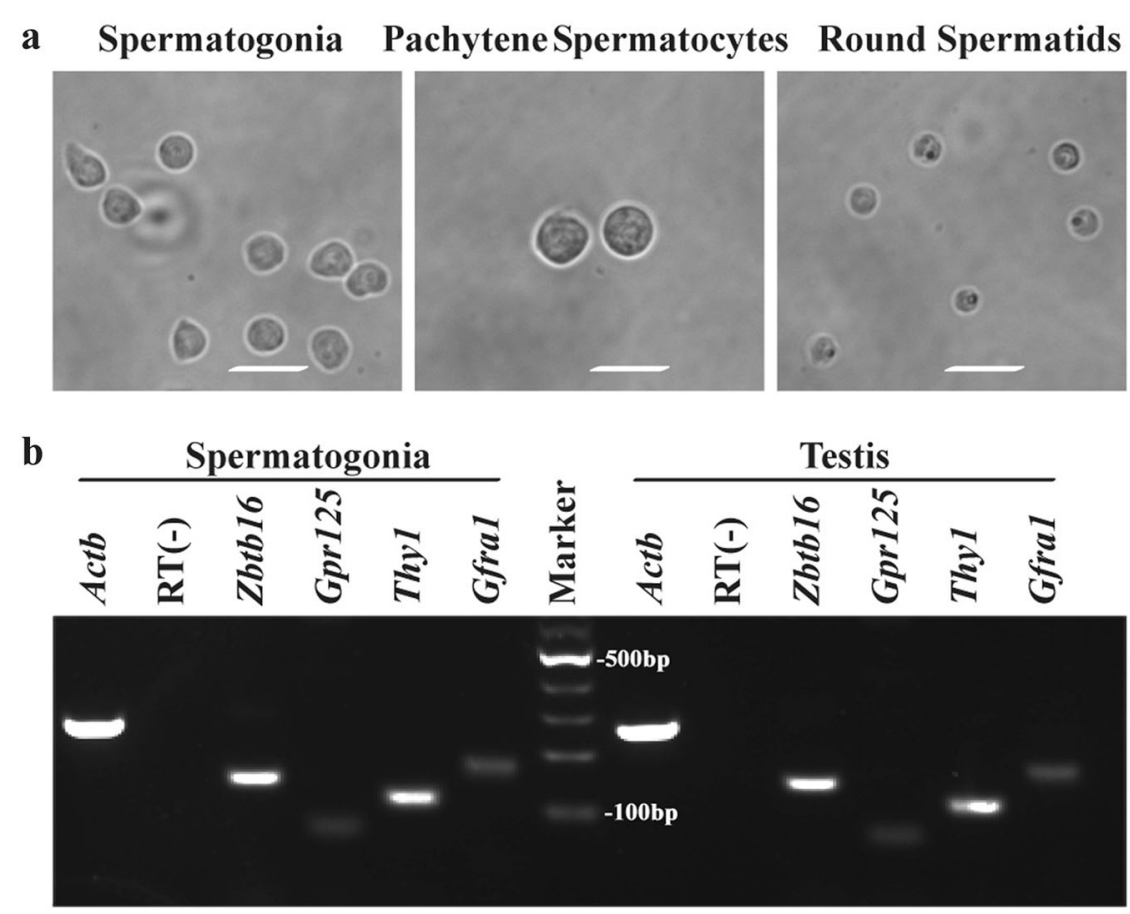

c PachyteneSpermatocytes

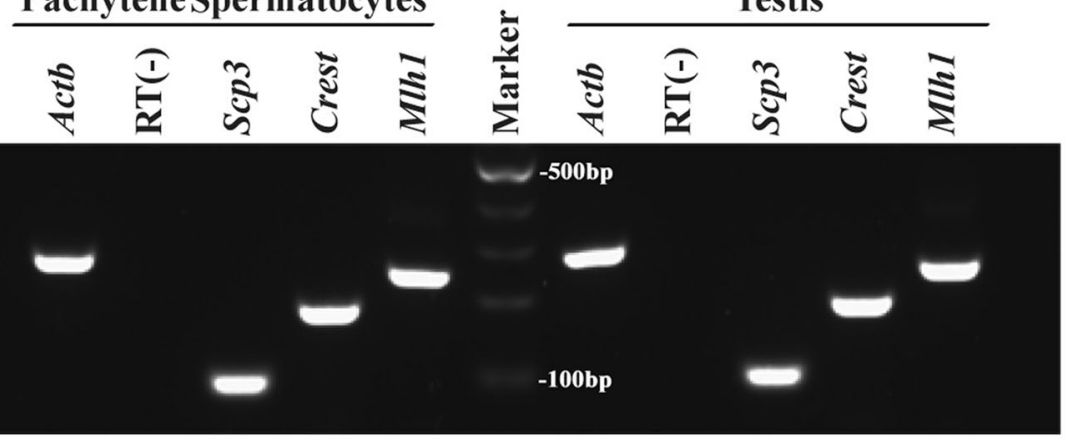

d Round Spermatids

Testis

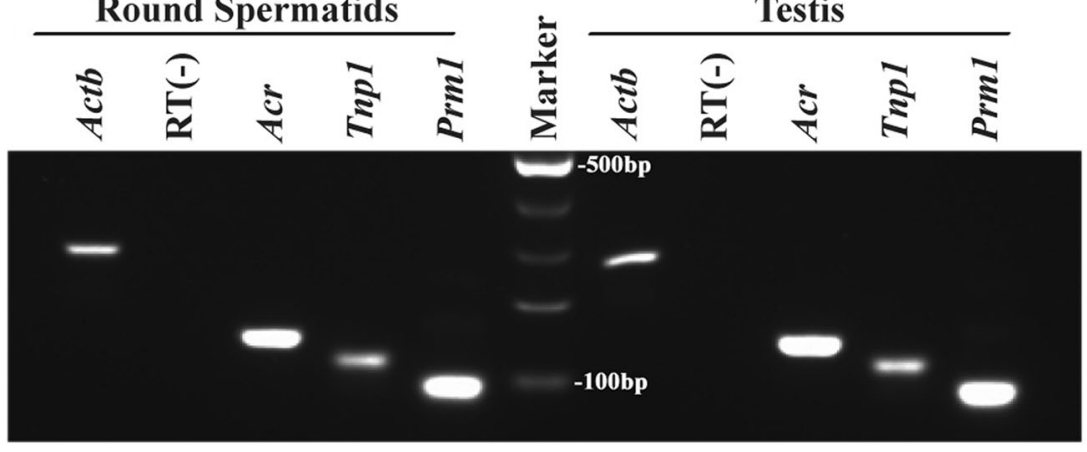

Fig. 5 The morphological and phenotypic characteristics of mouse spermatogonia, pachytene spermatocytes and round spermatids. Phase-contrast microscope showed the morphological characteristics of the freshly isolated spermatogonia, pachytene spermatocytes and round spermatids a. Scale bars in $\mathbf{a}=20 \mu \mathrm{m}$. RT-PCR revealed the transcripts of Gfra1, Thy1, Gpr125, and Zbtb16 in the freshly isolated mouse spermatogonia and mouse testis $\mathbf{b}$, MIh 1, Crest, and Scp3 in the freshly isolated pachytene spermatocytes and mouse testis $\mathbf{c}$, Acr, Prm 1, and Tnp 1 in the freshly isolated round spermatids and mouse testis $\mathbf{d}$. Actb was employed as a loading control of total RNA, and RNA samples without RT (RT-) but with PCR by Actb primers were used as negative controls 


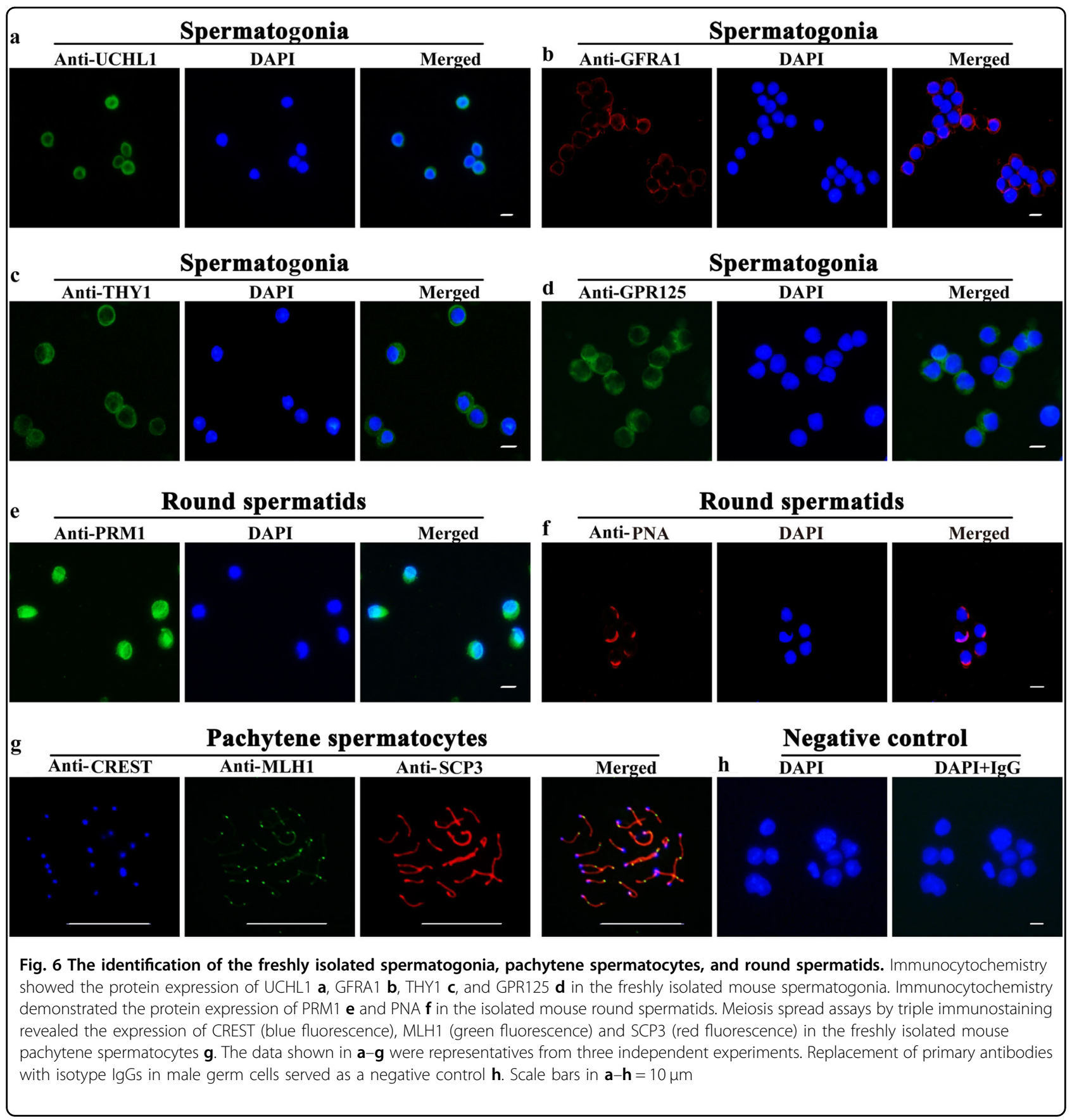

was conducted to identify the isolated pachytene spermatocytes. As shown in Fig. 6g, more than 90\% of tetraploid cells were co-expressing CREST (blue fluorescence), MLH1 (green fluorescence), and SCP3 (red fluorescence), markers for spermatocytes ${ }^{11}$. Replacement of primary antibodies with isotype IgGs served as negative controls, and no immunostaining was observed in male germ cells (Fig. 6h), thus verifying the specific immunostaining of these antibodies mentioned above. Immunocytochemistry demonstrated that the immunostaining of SCP3 and
PRM1 was not seen in isolated spermatogonia (Supplemental Fig. 2a), and UCHL1 and PRM1 were not detected in isolated pachytene spermatocytes (Supplemental Fig. 2b). The expression of UCHL1 and SCP3 was not observed in isolated round spermatids (Supplemental Fig. 2c). These data further verified the high purity of the isolated spermatogonia, pachytene spermatocytes, and round spermatids. In addition, the viability of these freshly isolated cells was over $95 \%$, as assessed with trypan blue exclusion assay (data not shown). 


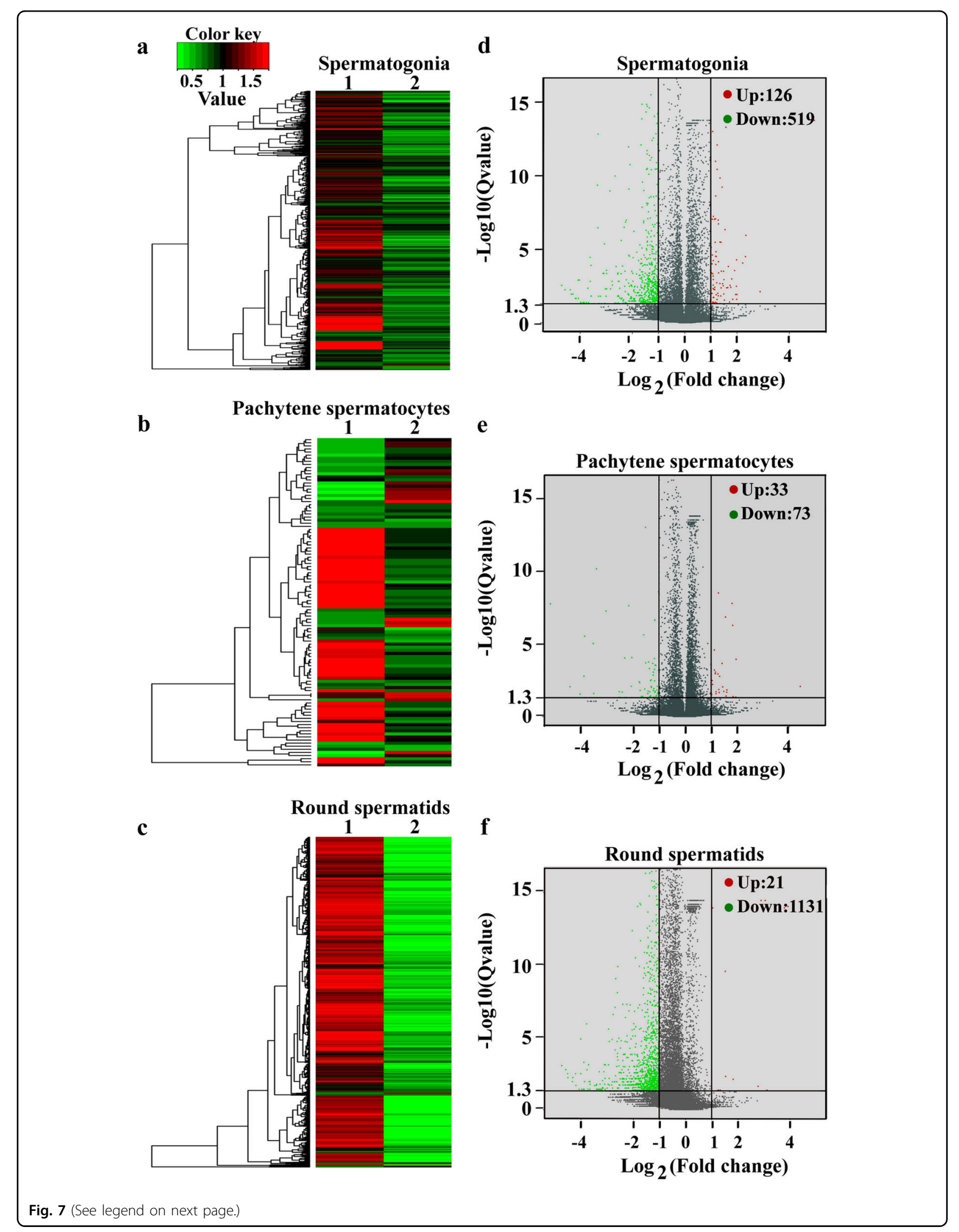


(see figure on previous page)

Fig. 7 RNA sequencing revealed distinct global transcription profiles in spermatogonia, pachytene spermatocytes and round spermatids between $\mathbf{P} 63^{(+/-)}$mice and wild-type mice. Hierarchical clustering analysis revealed the differentially expressed genes (DEGs) in spermatogonia $\mathbf{a}$, pachytene spermatocytes $\mathbf{b}$ and round spermatids $\mathbf{c}$ between $\mathrm{P} 63^{(+/-)}$mice and wild-type mice. Notes: ' 1 ' indicated wild-type mice and ' 2 ' denoted P $63^{(+/-)}$mice. Volcano plots showed the DEGs in spermatogonia $\mathbf{d}$, pachytene spermatocytes $\mathbf{e}$ and round spermatids $\mathbf{f}$ between P63 ${ }^{(+/-)}$mice and wild-type mice. The $\log _{2}$ scales of the expression signal values were plotted for all probes. Standard selection criteria to identify P63 ${ }^{(+/-)}$mice and wild-type mice was established at $\log _{2}$ (fold change) $>1$ and $p$-value $<0.05$. Upregulated and downregulated genes were represented by red and green color dots, respectively

Distinct global transcription profiles in spermatogonia, pachytene spermatocytes, and round spermatids between the $\mathrm{P} 63^{(+/-)}$mice and wild-type mice

To gain a novel insight into the molecular mechanisms of P63 in regulating the apoptosis of male germ cells and three stages of spermatogenesis, RNA sequencing was performed to compare the large scale of transcription profiles in spermatogonia, pachytene spermatocytes, and round spermatids between the $\mathrm{P} 63^{(+/-)}$mice and wild-type mice. Total RNA was extracted from these freshly isolated cells, and its quality was evaluated for RNA sequencing using electropherogram (Supplemental Fig. $3 \mathrm{a}-\mathrm{c}$ ) to ensure high quality. The total reads and gene numbers in spermatogonia, pachytene spermatocytes, and round spermatids of the $\mathrm{P} 63^{(+/-)}$mice and wild-type mice were shown in Table S2. Compared with wild-type mice, 519 genes were downregulated and 126 genes upregulated in spermatogonia of the P63 ${ }^{(+/-)}$mice (Fig. 7a, d). In total, 73 genes were downregulated while 33 genes were upregulated in pachytene spermatocytes of the $\mathrm{P} 63^{(+/-)}$mice compared to wild-type mice (Fig. 7b, e). In addition, 1131 genes were downregulated and 21 genes were upregulated in round spermatids of $\mathrm{P} 63^{(+/-)}$mice compared with wild-type mice (Fig. 7c, f). Together, these data implicate that $\mathrm{P} 63$ regulates three main stages of spermatogenesis transcriptionally.

\section{Verification of RNA sequencing data by quantitative real-time PCR}

To verify the results of RNA sequencing, quantitative real time PCR (Q-PCR) was conducted with three independent experiments. In total, 22 differentially expressed genes (DEGs) that were involved in apoptosis and spermatogenesis in mouse spermatogonia, pachytene spermatocytes and round spermatids were chosen randomly for verification. RNA sequencing showed the different expression levels of these DEGs in spermatogonia, pachytene spermatocytes, and round spermatids between P63 ${ }^{(+-)}$mice and wild-type mice (Fig. 8a). Real-time PCR further demonstrated the transcripts of 12 DEGs in spermatogonia (Fig. 8b), 4 DEGs in pachytene spermatocytes (Fig. 8c) and 6 DEGs in round spermatids (Fig. 8d) between $\mathrm{P} 63^{(+/-)}$mice and wild-type mice. Specifically, the transcription of Pomc, Pou5f2, Cdkn2d, Tgfa, Hes5,
Pld6, Pgk1, and Igfbp3 was statistically upregulated whereas the transcripts of Dazl, Zbtb16, Notch2, Stra8, Bmpr2, Insl3, Prlr, Cyp17a1, Fmrl, Junb, Csf1, Jun, Atm, and Dll1 were statistically downregulated in spermatogonia, pachytene spermatocytes, and round spermatids of $\mathrm{P} 63^{(+/-)}$mice compared with wild-type mice, which were completely consistent with the RNA sequencing results.

To unveil the relationship between P63 and the DEGs, ChIP-qPCR assay was conducted and demonstrated that P63 protein directly regulated Pomc, Pou5f2, Pgk1, Prlr, Jun, and Dll1 genes (Fig. 9b).

Gene ontology and pathway analysis of the DEGs in spermatogonia, pachytene spermatocytes, and round spermatids between the $\mathrm{P} 63^{(+/-)}$mice and wild-type mice

DAVID software (https://david.ncifcrf.gov) was used to perform gene ontology (GO) annotation on DEGs of spermatogonia, pachytene spermatocytes and round spermatids from $\mathrm{P} 63^{(+-)}$mice and wild-type mice. As shown in Table S3, there were 22 genes that were involved in the regulation of spermatogenesis, 28 genes that negatively controlled apoptosis, and 21 mRNAs that were related to the positive regulation of apoptosis in spermatogonia. There were 6 genes involved in the steroid biosynthetic process, 8 genes that were associated with the regulation of oxidation-reduction process, and 4 genes in the positive regulation of apoptosis in pachytene spermatocytes (Table S4). In total, 31 genes were involved in the regulation of apoptotic process, and 24 genes were associated with the positive regulation of apoptotic process in round spermatids; 10 genes were involved in the cell cycle arrest process, and 6 genes were related to sperm tail morphogenesis in round spermatids (Table S5).

Kyoto encyclopedia of genes and genomes (KEGG) pathway analysis was further carried out to elaborate the molecular mechanisms underlying the apoptosis and spermatogenesis. The detailed information of numerous signaling pathways was shown on the DEGs of spermatogonia (Table S6), pachytene spermatocytes (Table S7), and round spermatids (Table S8) between $\mathrm{P} 63^{(+/-)}$mice and wild-type mice, which sheds novel insights into molecular mechanisms of P63 in mediating three stages of spermatogenesis. 


\section{Discussion}

P53 family is composed of three transcription factors, namely P53, P63, and P73 ${ }^{17-19}$. In structure, P53, P63, and P73 are highly homologous in sequence. It has been showed that all three members of P53 family are expressed in mouse testis ${ }^{20}$. P53 plays an important role in the maintenance of genomic integrity in mammal, and it is involved in a variety of cellular functions, including the regulation of cell cycle, apoptosis, and DNA repair. It has been reported that P73 mutation reduces the proliferation and increases the apoptosis of male germ cells ${ }^{21}$. P63 is expressed in numerous tissues, including heart, epidermis, urothelium, cervix, testis, kidney, adrenal, thymus, and prostate, in humans and mice ${ }^{1}$. Here we have for the first time demonstrated that P63 mutation leads to the enhancement of early and late apoptosis of male germ cells in adult mice.

Spermatogenesis consists of the division of spermatogonia, meiosis of spermatocytes, and spermiogenesis of spermatids, which is regulated by various kinds of genetic and epigenetic factors. P63 protein is expressed during primordial germ cell (PGC) migration through hindgut epithelium and dorsal mesentery at E8.5-E11.5 ${ }^{22}$. P63 is continuously translated in female germ cells during meiotic arrest, and it protects the oocytes from apoptosis induced by irradiation $^{23,24}$. In male, P63 protein is localized in the nuclei of mouse testicular germ cells of embryos at different stages ${ }^{5,25}$. We found that P63 protein was present in the nuclei of spermatogonia, spermatocytes and round spermatids in adult wild-type mice and adult $\mathrm{P} 63^{(+/-)}$mice and that P63 mutation resulted in the decrease of $\mathrm{P} 63$ protein in adult mice. Although there was no remarkable difference in the size and weight of testes, fecundity, sperm motility, or progressive motility sperms between the $\mathrm{P} 63^{(+/-)}$mice and the wild-type mice, abnormally larger male germ cells were observed in seminiferous tubules of the $\mathrm{P} 63^{(+/-)}$mice, suggesting that P63 mutation causes the abnormality of male germ cells. These abnormal cells might be due to either incomplete differentiation or maturation of germ cells or a product of apoptosis, as evidenced by our morphologic and ultrastructure observation, which were similar to those cells in Bax or P53-null mouse testis ${ }^{26-28}$.

Significantly, we found that the percentages of both early and late apoptotic germ cells were increased in $\mathrm{P} 63^{(+/-)}$mice compared to wild-type mice, implicating that P63 mutation leads to cellular apoptosis in adult male mice. We identified, using RNA sequencing and real-time PCR, numerous DEGs that were involved in apoptosis, e.g., Insl3, Apc, Jun, Atm, Rara, Kitl, Lef1, Tgfa, Notch2, and Ccnd2. As examples, Insl3, a member of the insulin superfamily, is secreted by Leydig cells of both fetal and adult mammalian testis ${ }^{29,30}$. In Insl3 $3^{-1-}$ mice, the testicular development process and the epididymis are abnormal $^{31,32}$. There are normal development in the testis and epididymis of $\mathrm{P} 63^{(+/-)}$mice, which might be due to the fact that these mice are heterozygous mutation but not homozygous mutation. In boar testes, the apoptotic germ cells are increased by about fourfold after neutralizing INSL3 via up-regulating the pro-apoptotic CASP3 and BAX and downregulating the anti-apoptotic $\mathrm{XIAP}$ and $\mathrm{BCL} 2^{33}$. Apc is recognized as a substrate of Casp3 and it plays a key role in maintaining cellular homeostasis by the apoptotic surveillance ${ }^{34-36}$. In the AhCre Apc ${ }^{(\mathrm{fl} / \mathrm{fl})}$ adult mice, the frequency of apoptotic male mouse germ cells is increased, whereas pachytene spermatocytes, round spermatids, and elongating spermatids are statistically decreased ${ }^{37}$. In spermatogenesis, ataxia telangiectasia-mutated (Atm) plays a pivotal role in both premeiotic spermatogonial cells and premeiotic germ cell maintenance ${ }^{38,39}$, and it regulates cell cycle and apoptosis in response to DNA double-strand breaks (DSB), oxidative stress, and telomere eosin ${ }^{40,41}$. The Atm homozygous mutation mice are infertile, and the seminiferous tubules are completely devoid of mature gametes. Meanwhile, spermatogonia assume cell cycle arrest and are eliminated by apoptosis in Atm-null mice. In this study, the transcription of Atm was reduced in $\mathrm{P} 63^{(+/-)}$ mice, which was consistent with the fact that the early and late apoptotic germ cells were increased by P63 heterozygous mutation.

We also unveiled, using RNA sequencing and real-time PCR, a number of DEGs (e.g., Dazl, Zbtb16, Stra8, and Pou5f2) that were associated with regulating the spermatogenesis. Zbtb16, also known as Plzf, is a hallmark for human and mouse spermatogonial stem cells, and it plays a crucial role in maintaining spermatogonial self-renewal. Silencing the Zbtb16 function leads to spermatogonial differentiation $^{42,43}$. The self-renewal capability of spermatogonial stem cells is reduced progressively in mice lacking $Z b t b 16$, and an increase in apoptosis and loss of seminiferous tubule structure occur ${ }^{42}$. Deleted in azoospermia-like (DAZL) protein, a homolog of the deleted in azoospermia (DAZ), is expressed in the nuclei and cytoplasm of germ cells at all stages of spermatogenesis in humans, mice, and pigs ${ }^{44-47}$. The abnormal expression of DAZL affects about $10 \%$ of males with azoospermia or oligozoospermia ${ }^{48-50}$. Although the heterozygous (Dazl $\alpha^{\mathrm{Tm} 1 \mathrm{Hgu} /+}$ ) male mice are fertile, about $60 \%$ of the sperm is visibly abnormal, and there is no sperm in the Dazl $\alpha^{\text {Tm1Hgu/Tm1Hgu }}$ epididymid. Stimulated by retinoic acid 8 (Stra 8 ) induced by retinoic acid (RA) can trigger the onset of meiosis both in male and female gonads ${ }^{51,52}$. In males, Stra 8 is firstly expressed in spermatogonia at post-natal day 5 , and its level is increased in premeiotic spermatocytes ${ }^{53}$. It has been reported that Stra 8 is dispensable for the meiotic initiation and required for the progression of the meiotic prophase. 
Spermatogenesis is severely disrupted, and only spermatogonia and somatic cells are present in about $20 \%$ of the seminiferous tubules of $\mathrm{Stra}^{(-1-)}$ mice $^{54}$. In addition, our GO analysis revealed that numerous DEGs, e.g., Dync1h1, Dnah2, Kif4, Kif5b, Chst11, and Med12, were involved in the microtubule-based movement and post-anal tail morphogenesis. These genes have been shown to affect the maturation of male gametes ${ }^{55-58}$. In this study, we found that the percentages of abnormal sperm with round-headed spermatozoa, cytoplasmic droplet, and abnormal sperm tail were increased in $\mathrm{P} 63^{(+/-)}$mice, which indicates that P63 plays an important role in the maturation of male gametes in adult mice.

As P53, P63, and P73 are highly homologous in sequence structure, we compared the DEGs in $\mathrm{p} 63^{(+/-)}$ mice with the targeting genes of P53 and P73 to determine whether the DEGs are uniquely regulated by P63. Among the 22 DEGs of P63, it has been shown that Pomc $^{59,60}$, Notch $^{61}, \operatorname{Igfbp}^{62}{ }^{6}$ Jun $^{63}, \mathrm{Csf1}^{64}$, and $\mathrm{Atm}^{65}$ are the targeting genes of P53, while $\operatorname{Igfbp} 3^{66}$ and $J u n^{67}$ are the targets of P73. Hes $5^{68}, \operatorname{Igfbp} 3^{69}, \mathrm{Jun}^{70}$, and $\mathrm{Atm}^{71}$ have been demonstrated to be the target genes of P63. Notably, we identified Pou5f2, Pgk1, Prlr, and Dll1 as the target genes of P63 by ChIP-qPCR.

In summary, we have utilized $\mathrm{P} 63^{(+/-)}$mice to identify the role and transcriptional regulation of P63 in mediating the apoptosis and adult mouse spermatogenesis. We found that $\mathrm{P} 63^{(+/-)}$mutation resulted in the abnormalities of male germ cells and significant increase of apoptosis in male germ cells. Notably, we have uncovered a number of genes that might be associated with regulating apoptosis and three stages of spermatogenesis. This study thus provides new insights into the death of male germ cells and molecular mechanisms underlying mammalian spermatogenesis. This study could offer new targets for the diagnosis and therapy of male infertility.

\section{Materials and Methods}

\section{Experimental animals}

All mice were fed in the animal center at Renji Hospital, School of Medicine Shanghai Jiao Tong University with controlled temperature and humidity. This study was approved by the Institutional Ethical Review Committee of Ren Ji Hospital, School of Medicine, Shanghai Jiao Tong University. All experimental protocols were performed according to relevant guidelines and regulations of the Institutional Ethical Review Committee of Ren Ji Hospital. The $P 63^{\mathrm{Brdm} 2}$ mice were a kind gift from the laboratory of Dr. Weiqiang Gao (Ren Ji Hospital, School of Medicine, Shanghai Jiao Tong University $)^{7,72} \cdot \mathrm{P}_{63} 3^{(+/-)}$ male mice were crossed with wild-type female mice to generate the offspring of $\mathrm{P} 63^{(+-)}$mice. The genotype of P $63^{(+/-)}$mice was determined by PCR analysis using the primer sequences and procedures provided by the Jackson
Laboratory (https://www2.jax.org/protocolsdb/f? $\mathrm{p}=116: 5: 0:: N O: 5: P 5 \_M A S T E R \_P R O T O C O L \_I D$, P5_JRS_CODE:5248,003568). For P63 ${ }^{(+/-)}$genotype, the $p 63^{\mathrm{Brdm} 2}$ fragments were amplified by using the following primers: 5'-GTGTTGGCAAGGATTCTGAGACC-3' (forward), 5'-GGAAGACAATAGCAGGCATGCTG-3' (reverse). For fecundity assessment, wild type and P63 ${ }^{(+/-)}$males at 2-8 months old were separately mated with wild-type females for 6 months, and wild type and $\mathrm{P} 63^{(+/-)}$males at around 12 months old were separately mated with wild-type females for 2 months.

\section{Sperm motility analysis of $\mathrm{P}_{63}^{(+/-)}$mice and wild type}

The sperm motility assay of $\mathrm{P} 63^{(+/-)}$mice and wild-type mice was performed in terms of the method as previously described $^{73}$. In total, $6.3 \pm 1.6 \times 10^{6}$ sperm $(n=3)$ from wild-type mice and $5.2 \pm 0.9 \times 10^{6}$ sperm $(n=3)$ from $\mathrm{P} 63^{(+/-)}$mice were used to assess the sperm motility and progressive motility. After being euthanized by cervical dislocation, caudal epididymis was immediately excised from the mice. The epididymis was placed into a glass tube containing $1 \mathrm{ml}$ Enriched Krebs-Ringer Bicarbonate (EKRB) medium pre-warmed to $37^{\circ} \mathrm{C}$. The caudal epididymis was cut into small fragments with scissors, and spermatozoa were released into the medium. After $5 \mathrm{~min}$, sperm suspension was put into a Sperm Analysis Chamber (Hamilton Thorne Research, Beverly, USA) and analyzed with a computer-assisted semen analysis (CASA) by the HTM-TOX IVOS sperm motility analyzer (Animal Motility, version 12.3 A, Hamilton Thorne Research). The instrument settings used for the analysis were as follows: temperature, $37^{\circ} \mathrm{C}$; minimum cell size, five pixels; minimum contrast, 50; minimum static contrast, 25; low average path velocity cutoff, 20.0; low straight-line velocity cutoff, 30.0; threshold straightness, $50 \%$; static head size, 0.3-1.95; static head intensity, 0.5-1.3; and magnification, 0.89 . Thirty frames were acquired at a frame rate of $60 \mathrm{~Hz}$, and the playback feature was set during the analysis to check the accuracy. The data of the sperm motility were obtained from three independent experiments.

\section{Transmission electron microscopic (TEM) assay of sperm of $\mathrm{P} 63^{(+/-)}$mice and wild-type mice}

The sperms from caudal epididymis of $\mathrm{P}_{6}{ }^{(+/-)}$mice and wild-type mice were obtained as described above. After being fixed with $2.5 \%$ glutaraldehyde in $0.1 \mathrm{M}$ phosphate buffer $(\mathrm{pH}=7.4)$, the ultrastructure of sperm was examined by TEM assay according to the method as previously described ${ }^{74}$. Briefly, the sperm was fixed in $1 \%$ osmium tetroxide solution for $2 \mathrm{~h}$, followed by dehydration in a graded series of acetone, and embedded in epoxy resin. Ultrathin sections were sectioned and stained with uranyl acetate and lead citrate. The sections of sperm 
were examined under a transmission electron microscope (HITACHI, H-7650, Japan).

\section{Hematoxylin-eosin staining of mouse testes and sperm from $\mathrm{P} 63^{(+/-)}$mice and wild-type mice}

$\mathrm{P} 63^{(+/-)}$mice and wild-type mice were killed by cervical dislocation, and testes were immediately fixed in $4 \%$ formaldehyde (PFA) overnight. The testis tissues were dehydrated in $30 \%$ sugar solution for $24 \mathrm{~h}$ at $4{ }^{\circ} \mathrm{C}$, and they were embedded in optimum cutting temperature compound (OTC) and sectioned at $8 \mu \mathrm{m}$ thicknesses. Testis sections and sperm were stained with hematoxylin-eosin (H\&E) pursuant to the method as previously describe ${ }^{75}$. In brief, the testis sections and sperm from $\mathrm{P} 63^{(+/-)}$mice and wild-type mice were obtained and fixed in 4\% PFA for 10-15 min, and they were stained with hematoxylin for $15 \mathrm{~min}$ and followed by eosin for about $2 \mathrm{~min}$ at room temperature. H\&E staining of testes and sperm was observed under a phase-contrast microscope, and the percentage of abnormal sperm was counted out of 500 total cells from three independent experiments.

\section{Isolation of male germ cells from $\mathrm{P} 63^{(+/-)}$and wild-type mice using two-step enzymatic digestion and the differential plating}

Two-step enzymatic digestion and the differential plating were utilized to isolate male germ cells from mouse testes of $\mathrm{P} 63^{(+/-)}$and wild-type mice according to the protocol described previously ${ }^{76}$. The testicular tissues from $\mathrm{P} 63^{(+-)}$and wild-type mice were washed three times with Dulbecco modified Eagle medium (DMEM) (Gibco) containing 2\% penicillin and streptomycin (Gibco). The testis tissues were minced by scissors to become a semi-liquid state and then incubated with $10 \mathrm{ml}$ DMEM containing $2 \mathrm{mg} / \mathrm{mL}$ type IV Collagenase (Gibco) and $10 \mu \mathrm{g} / \mathrm{ml}$ DNase I (Sigma, Saint Louis, USA) in a shaking water bath at $34{ }^{\circ} \mathrm{C}$ at 100 r.p.m. for $10 \mathrm{~min}$. The enzymatic digestion of testis tissues was stopped by $10 \mathrm{ml}$ DMEM containing 10\% FBS whenever there were only seminiferous tubules. After $5 \mathrm{~min}$ of sedimentation, the seminiferous tubules were incubated with $10 \mathrm{ml}$ DMEM including $2.5 \mathrm{mg} / \mathrm{mL}$ type IV collagenase, $2 \mathrm{mg} / \mathrm{ml}$ Hyaluronidase (Sigma), $2 \mathrm{mg} / \mathrm{ml}$ Trypsin (Sigma) and $10 \mu \mathrm{g} /$ $\mathrm{ml}$ DNase I in oscillating water bath at $34^{\circ} \mathrm{C}, 100$ r.p.m. for $10-15 \mathrm{~min}$. After centrifugation at $300 \times g$ for $5 \mathrm{~min}$, the supernatant was removed. The sediment was resuspended in DMEM/F-12 (Gibco) supplemented with $10 \% \mathrm{FBS}$, and cell suspension was filtered through a $40 \mu \mathrm{m}$ nylon mesh to remove cell aggregates. The cell mixture was seeded in a $10 \mathrm{~cm}$ dish pre-coated with gelatin, and they were cultured at $34{ }^{\circ} \mathrm{C}$ in $5 \% \mathrm{CO}_{2}$ for $24 \mathrm{~h}$. Somatic cells, including sertoli cells, leydig cells, and myoid cells, were attached to culture dishes, and male germ cells remained in suspension.
Isolation of spermatogonia, pachytene spermatocytes, and round spermatids from $\mathrm{P}_{63}{ }^{(+/-)}$mice and wild-type mice by STA-PUT velocity sedimentation

The STA-PUT method, using a linear bovine serum albumin (BSA) (Sigma) gradient and sedimentation, was utilized to separate spermatogonia, pachytene spermatocytes, and round spermatids from $\mathrm{P} 63^{(+/-)}$mice and wildtype mice in terms of the size, mass and gravity of heterogeneous cells. Male germ cells were obtained using two-step enzymatic digestion and followed by the differential plating from $\mathrm{P} 63^{(+/-)}$mice and wild-type mice at 2 months old, and spermatogonia, pachytene spermatocytes, and round spermatids were isolated by STA-PUT velocity sedimentation from $\sim 5 \times 10^{7}$ male germ cells according to the protocol as we described previously ${ }^{11}$. In terms of cell diameter and morphology under microscope, 5-25 fraction collections were chosen as the pachytene spermatocytes, and 35-50 fraction collections were selected as spermatogonia. In addition, 60-75 fraction collections were regarded as round spermatids. An aliquot of each cell fraction was examined carefully under a phase-contrast microscope to assess cellular integrity and identify of each cell type. Trypan blue staining was performed to assess the viability of the freshly isolated germ cells. Briefly, the freshly isolated germ cells were stained with $0.4 \%$ trypan blue for $3-5 \mathrm{~min}$, and the viability of these cells was assessed by the percentage of the cells excluding trypan blue and total cells counted. RT-PCR, immunocytochemistry and meiotic spread assays were used to determine the phenotype and purity of the isolated spermatogonia, pachytene spermatocytes and round spermatids. The mRNA was extracted from spermatogonia, pachytene spermatocytes, and round spermatids of $\mathrm{P} 63^{(+/-)}$and wild-type mice for RNA sequencing.

\section{PCR for Trp63 ${ }^{\mathrm{Brdm} 2}$ and $\mathrm{P} 63$ allele in $\mathrm{P} 63^{(+/-)}$and wild-type mice}

Genomic DNA was extracted from tails of $\mathrm{P} 63^{(+/-)}$and wild-type mice using DNA extraction kit (Biomed, PC3201, China). The primer sequences of P63 and Actb were designed and listed in Table S1. The PCR reactions started at $94{ }^{\circ} \mathrm{C}$ for $2 \mathrm{~min}$ and were performed pursuant to the following conditions: denaturation at $94{ }^{\circ} \mathrm{C}$ for $30 \mathrm{~s}$, annealing at $60^{\circ} \mathrm{C}$ for $45 \mathrm{~s}$, and elongation at $72{ }^{\circ} \mathrm{C}$ for 45 $\mathrm{s}$, for 26 cycles. The PCR samples were incubated for an additional $5 \mathrm{~min}$ at $72{ }^{\circ} \mathrm{C}$. PCR products were separated by electrophoresis with $2 \%$ agarose gel and they were visualized with ethidium bromide.

\section{RNA extraction and reverse transcription (RT) and real-time quantitative PCR}

Total RNA was extracted from spermatogonia, pachytene spermatocytes, and round spermatids of $\mathrm{P} 3^{(+-)}$ mice and wild-type mice using Trizol (Takara, Kusatsu, 
Japan). The concentrations of total RNA were measured by Nanodrop (Thermo), and RIN (RNA integrity number) of $>7$ of total RNA was used to ensure good quality. The First Strand cDNA Synthesis Kit (Thermo Scientific, USA) was used to conduct reverse transcription (RT) of total RNA, and PCR of the cDNA was carried out according to the protocol as we described previously ${ }^{77}$. The primer sequences of the chosen genes for RT-PCR were designed and listed in Table S1. The PCR reactions started at $94^{\circ} \mathrm{C}$ for $2 \mathrm{~min}$ and were performed in terms of the following conditions: denaturation at $94{ }^{\circ} \mathrm{C}$ for $30 \mathrm{~s}$, annealing at $55-60^{\circ} \mathrm{C}$ for $45 \mathrm{~s}$ as listed in Table S1, and elongation at $72^{\circ} \mathrm{C}$ for $45 \mathrm{~s}$, for 35 cycles. The PCR samples were incubated for an additional $5 \mathrm{~min}$ at $72^{\circ} \mathrm{C}$. RNA without RT (RT-) but with PCR served as a negative control. PCR products were separated by electrophoresis with $2 \%$ agarose gel and they were visualized with ethidium bromide.

Quantitative real-time PCR reactions were conducted using Power SYBR Green PCR Master Mix (Applied Biosystems, Woolston Warrington, UK) and a 7500 fast real-time PCR system (Applied Biosystems, Carlsbad, CA, USA). The primer sequences of the chosen genes for real-time PCR were designed and listed in Table S1. The comparative CT (Threshold Cycle) method was used to quantify the PCR products. The CT value of gene was normalized against the threshold value of mice housekeeping gene $A c t b\left[\Delta \mathrm{CT}=\mathrm{CT}_{(\mathrm{Gene})}-\mathrm{CT}_{(A c t b)}\right]$, and the relative expression of gene in $\mathrm{P} 63$ mutation mice to the wild-type mice was calculated by formula $2^{-\Delta \Delta \mathrm{CT}}\left[\Delta \Delta \mathrm{CT}=\Delta \mathrm{CT}_{(\mathrm{P} 63 \text { mutation) }}-\Delta \mathrm{CT}\right.$ (wild type) $]$.

\section{Immunocytochemistry}

For immunocytochemistry, freshly isolated spermatogonia and round spermatids from $\mathrm{P} 63^{(+/-)}$and wild-type mice were fixed with 4\% PFA for 15-30 min, and they were washed three times with cold PBS (Medicago, Uppsala, Sweden) and permeabilized with $0.4 \%$ Triton X100 (Sigma) for 5-15 min. After extensive washes with PBS, these cells were blocked in 5\% BSA for $1 \mathrm{~h}$ at room temperature and followed by incubation with primary antibodies, including GPR125 (Abcam, ab51705, 1:200), GFRA1 (Abcam, ab8026, 1:200), UCHL1 (AbDSerotec, MCA4750, 1:200), THY1 (Abcam, ab133350 1:200), PRM1 (Santa Cruz Biotechnology, sc-30173, 1:200) overnight at $4{ }^{\circ} \mathrm{C}$. The specificity of these antibodies was evaluated previously and verified to be great ${ }^{11}$. After extensive washes with PBS, the cells were incubated with IgGs conjugated with fluorescein isothiocyanate (FITC) (Sigma) or rhodamine-conjugated IgG (Sigma), at a 1:200 dilution for $1 \mathrm{~h}$ at room temperature. Replacement of primary antibodies with isotype IgGs in mouse male germ cells served as negative controls. DAPI (4, 6-diamidino-2phenylindole) was employed to label the cell nuclei, and the images were captured with a Nikon microscope (Tokyo, Japan).

\section{Meiotic spread assays}

Meiotic spread assays were performed to determine the identity and the purity of the freshly isolated pachytene spermatocytes from $\mathrm{P} 63^{(+/-)}$and wild-type mice testis by STA-PUT velocity sedimentation pursuant to the method described previously ${ }^{11}$. Briefly, cells were lysed by a hypotonic solution and spread evenly over slides layered with $1 \%$ PFA and $0.15 \%$ Triton X-100. Slides were dried for $24 \mathrm{~h}$ at room temperature in a humid chamber. The cells were treated with $0.04 \%$ photoflo for $5 \mathrm{~min}$ and blocked with $4 \%$ goat serum. The cells were incubated with primary antibodies, including SCP3 (Abcam, ab15093, 1:100), MLH1 (BD Pharmingen, 551092, 1:50) and CREST (Immunovision, HCT-0100, 1:80), overnight at $37^{\circ} \mathrm{C}$ in a humid chamber. Donkey anti-rabbit $\operatorname{IgG}(\mathrm{H}+\mathrm{L}$ ) (Alexa Fluor 555, Molecular Probes, A31572, 1:250), Alexa Fluor 488 goat anti-mouse IgG1 $(\gamma 1)$ (AF488, Molecular Probes, A-21121, 1:120) and AMCA-conjugated affiniPure donkey anti-human $\operatorname{IgG}(\mathrm{H}+\mathrm{L})$ (Jackson ImmunoResearch, 709-155-149, 1:200) were used as the secondary antibodies and incubated for $90 \mathrm{~min}$ at $37^{\circ} \mathrm{C}$. After washing three times with cold TBS, the cells were observed with a fluorescence microscope (Nikon, Tokyo, Japan).

\section{PNA-FITC staining}

Acrosome integrity of round spermatids from $\mathrm{P} 63^{(+/-)}$ and wild-type mice was detected by PNA-FITC staining. Briefly, the isolated round spermatids were fixed in $4 \%$ PFA for $10-15 \mathrm{~min}$. After washing with PBS three times per $5 \mathrm{~min}$, the cells were incubated with PNA-FITC (Invitrogen, 1:300) for $30 \mathrm{~min}$ at room temperature. DAPI (4, 6-diamidino-2-phenylindole) was employed to label the cell nuclei, and the images were captured with a Nikon microscope.

\section{Immunohistochemistry}

Testis sections of $\mathrm{P} 63^{(+/-)}$mice and wild-type mice were deparaffinized by xylene three times, and hydrated with a series of graded alcohol and treated with $3 \% \mathrm{H}_{2} \mathrm{O}_{2}$ (Boster Biological Technology, Guangzhou, China) for 10 min at room temperature to block the endogenous peroxidase activity. After blocking with 5\% BSA for $1 \mathrm{~h}$ at room temperature, the sections were incubated with primary antibody against P63 (Abcam, ab735, 1:200) overnight at $4{ }^{\circ} \mathrm{C}$. After extensive washes with $\mathrm{PBS}$, the sections were incubated with HRP conjugated second antibody for $1 \mathrm{~h}$ at room temperature. After extensive washing with PBS, DAB (3, 3-diaminobenzidine) (Zhongshanjinqiao Biotechnology, Beijing, China) was used to label the P63 protein. Finally, the sections were 
stained with hematoxylin and observed under a Nikon microscope.

\section{TUNEL assay}

The apoptosis percentages of male germ cells in testis sections of wild-type mice and $\mathrm{P} 63^{(+/-)}$mice were detected using the TUNEL Apoptosis Detection Kit pursuant to the manufacturer's instruction (YEASEN, China). Testis sections of wild type and $\mathrm{P} 63^{(+/-)}$mice were deparaffinized by xylene for three times, and they were hydrated with a series of graded alcohol. After being treated with $20 \mu \mathrm{g} / \mathrm{ml}$ proteinase $\mathrm{K}$ (YEASEN, China) for $20 \mathrm{~min}$ at room temperature, the sections were incubated with FITC-12-dUTP labeling/TdT enzyme buffer for $1 \mathrm{~h}$ in dark, and PBS without TdT enzyme was used as the negative control. Propidium iodide (PI) was used to label the nuclei, and images were observed under a Nikon microscope. The percentages of TUNEL-positive cells were counted in at least 500 cells, and three independent experiments were performed.

\section{Western blots}

Male germ cells from wild-type mice and $\mathrm{P} 63^{(+/-)}$mice were lysed with RIPA buffer (BiotechWell, Shanghai, China) for $30 \mathrm{~min}$ on ice. Cell lysates were cleared by centrifugation at $12,000 \times \mathrm{g}$ for $15 \mathrm{~min}$ at $4{ }^{\circ} \mathrm{C}$, and the protein concentrations were measured by BCA kit (DingGuo ChangShengBiotech, Beijing, China). In total, $30 \mathrm{mg}$ of cell lysate from each sample were separated using 10\% SDS-PAGE (Bio-Rad Laboratories) and transferred to nitrocellulose membranes for $2 \mathrm{~h}$ at room temperature. The membranes were blocked using $5 \%$ nonfat dry milk in TBS-T for $1 \mathrm{~h}$ at room temperature. After washing with TBS-T, the membranes were incubated with antibodies against P63 (Abcam, ab735, 1:500) and ACTB (Protein tech, catalog no: HRP-60008, dilution: 1:5000) overnight at $4{ }^{\circ} \mathrm{C}$. After extensive washes, the membranes were incubated with horseradish peroxidase-conjugated immunoglobulin G (IgG) (Santa Cruz Biotechnology) at a 1:2000 dilution for $1 \mathrm{~h}$ at room temperature. The membranes were detected by chemiluminescence (Chemi-Doc XRS, Bio-Rad, Hercules, CA, USA), and densitometric analyzes were processed with Adobe Photoshop 8.0. The relative level of $\mathrm{P} 63$ protein was normalized to the expression of ACTB.

\section{Annexin V/propidium iodide (PI) staining and flow cytometry}

The apoptosis percentages of male germ cells of wild type and $\mathrm{P} 63^{(+/-)}$mice were detected using the Annexin VFITC/PI kit by flow cytometry pursuant to the manufacturer's instruction (Biolegend, London, UK). Male germ cells were obtained from P63 ${ }^{(+/-)}$mice and wild-type mice using two-step enzyme and followed by the differential plating and culture for $24 \mathrm{~h}$. It was feasible to identify and quantify apoptotic cells by conjugating FITC to Annexin V using flow cytometry. The cells were simultaneously stained with Annexin V-FITC (green fluorescence) and the non-vital dye PI (red fluorescence), which allowed the discrimination of intact cells $\left(\mathrm{FITC}^{-} \mathrm{PI}^{-}\right)$, early apoptotic $\left(\mathrm{FITC}^{+} \mathrm{PI}^{-}\right)$and late apoptotic or necrotic cells $\left(\mathrm{FITC}^{+} \mathrm{PI}^{+}\right)$. The procedure was carried out according to the protocol as described previously ${ }^{77}$.

\section{RNA sequencing}

Total RNAs were extracted from spermatogonia, pachytene spermatocytes, and round spermatids of $\mathrm{P} 63^{(+-)}$mice and wild-type mice with Trizol reagent (Invitrogen, Carlsbad, CA, USA). The quantity and purity of total RNA were analyzed with Agilent 2100 Bioanalyzer (Agilent RNA 6000 Nano Kit) with RIN >7.0. The cDNA libraries were used for sequencing on an Illumina HiSeq 2500 instrument. RNA sequencing libraries were established for two RNA sequencing samples (three mice per sample) at Guangzhou RiboBio Co., Ltd (Guangzhou, China) using the NEBNext Ultra RNA Library Prep Kit (Illumina, San Diego, USA), and the procedures and standards were performed in terms of the manufacture's manual. A computational pipeline was employed to process RNA-sequencing data. Clean reads were obtained after the raw reads were filtered with adaptor skewer ${ }^{78}$, and sequencing data were mapped to mouse genome mm10 RefSeq with Tophat version 2.0.13 with default parameters ${ }^{79}$. Gfold version 1.1.2 was used to produce biologically meaningful rankings of differentially expressed genes (DEGs) ${ }^{80}$. Subsequently, those DEGs were assessed by Audics using RPKM ${ }^{81}$, and the significantly DEGs were selected according to the following criteria: $p<0.05$ and fold change $\geq 2$.

\section{Chromatin immunoprecipitation-qPCR assay}

Chromatin immunoprecipitation (ChIP) assay was performed according to the manufacturer's instruction (Beyotime Biotechnology, P2078, China). Human spermatogonia, pachytene spermatocytes and round spermatids were isolated from wild-type mice using STA-PUT, and they were cross-linked with $1 \%$ formaldehyde for $10 \mathrm{~min}$ at $37^{\circ} \mathrm{C}$. After terminating with $125 \mathrm{mM}$ glycine solution and washing with PBS, the cells were lysed with lysis buffer containing $1 \mathrm{mM}$ PMSF for $10 \mathrm{~min}$ in ice-bath. Chromatin solutions were sonicated to 300-700 bp DNA fragments using sonicator. After being diluted with chip dilution buffer, 20 $\mu \mathrm{l}$ samples were taken out for input control. The sonicated DNA fragments were incubated with antiIgG (Sigma) or anti-P63 antibody (Abcam) overnight at $4^{\circ} \mathrm{C}$. Immunocomplexes were washed with low salt buffer, high-salt buffer, and $\mathrm{LiCl}$ buffer, and they were 
eluted with elution buffer (1\% SDS, $0.1 \mathrm{M} \mathrm{NaHCO}_{3}$ ). Cross-links were reversed at $65^{\circ} \mathrm{C}$ for $4 \mathrm{~h}$. DNA was purified using PCR purification Kit (Beyotime biotechnology, P2078, China). Enrichment was measured using qPCR, and the primers of genes were listed in Supplemental Table S1. Fold enrichment was calculated using the comparative threshold cycle method using the formula $2^{-\Delta \Delta C T}$ as mentioned above.

\section{Statistical analysis}

All data were presented as mean $\pm \mathrm{SD}$ and analyzed by Student's $t$-test or one way ANOVA with the appropriate post hoc tests using Prism (version 5, GraphPad Software). Normality and homogeneity of variances were checked prior to conduct Student's $t$-test or one way ANOVA, and $P<0.05$ was considered statistically significant.

\section{Acknowledgments}

The authors thank Dr. Weiqiang Gao, Professor at School of Medicine, Shanghai Jiao Tong University, for providing the $P 63^{\mathrm{Brdm} 2}$ mice. This work was supported by grants from the National Nature Science Foundation of China (31230048, 31671550, and 31401250) and Chinese Ministry of Science and Technology (2016YFC1000606, 2014CB943101), the Program for Professor of Special Appointment (Eastern Scholar) at Shanghai Institutions of Higher Learning (2012.53), Shanghai Municipal Education Commission-Gaofeng Clinical Medicine Grant Support (20152511), and Shanghai Hospital Development Center (SHDC12015122)

\section{Author details}

${ }^{1}$ State Key Laboratory of Oncogenes and Related Genes, Renji- Med X Clinical Stem Cell Research Center, Ren Ji Hospital, School of Medicine, Shanghai Jiao Tong University, Shanghai 200127, China. ${ }^{2}$ Shanghai Institute of Andrology, Ren Ji Hospital, School of Medicine, Shanghai Jiao Tong University, 145 Shangdong Road, Shanghai 200001, China. ${ }^{3}$ Shanghai Key Laboratory of Assisted Reproduction and Reproductive Genetics, Shanghai 200127, China.

${ }^{4}$ Shanghai Key Laboratory of Reproductive Medicine, Shanghai 200025, China

\section{Author contributions}

H.W. performed the experiments, wrote the manuscript and helped data analysis. M.N. assisted with the experiments and managed mice; Q.Y. assisted with the experiments and ordered reagents; W.Z. assisted with the experiments; L.W. assisted with the experiments; H.F. assisted with the experiments; F.Z. assisted with the experiments; Z.H. was responsible for the conception and design, supervision of all aspects of the laboratory experiments, data analysis, writing the manuscript and final approval of the manuscript. All authors approved the manuscript.

\section{Competing financial interests}

The authors declare that they have no financial interests.

Publisher's note: Springer Nature remains neutral with regard to jurisdictional claims in published maps and institutional affiliations.

\section{Supplementary information}

The online version of this article (https://doi.org/10.1038/s41419-017-0046-z) contains supplementary material.

Received: 9 June 2017 Revised: 6 September 2017 Accepted: 9 October 2017

Published online: 23 January 2018

\section{References}

1. Yang, A. et al. p63, a p53 homolog at 3q27-29, encodes multiple products with transactivating, death-inducing, and dominant-negative activities. Mol. Cell 2, 305-316 (1998)

2. Wu, G. et al. DeltaNp63alpha and TAp63alpha regulate transcription of genes with distinct biological functions in cancer and development. Cancer Res. 63, 2351-2357 (2003)

3. Westfall, M. D. \& Pietenpol, J. A. p63: Molecular complexity in development and cancer. Carcinogenesis 25, 857-864 (2004).

4. Thanos, C. D. \& Bowie, J. U. p53 Family members p63 and p73 are SAM domain-containing proteins. Protein Sci. 8, 1708-1710 (1999).

5. Nakamuta, N. \& Kobayashi, S. Developmental expression of p63 in the mouse testis. J. Vet. Med. Sci. 66, 681-687 (2004).

6. Petre-Lazar, B. et al. The role of p63 in germ cell apoptosis in the developing testis. J. Cell Physiol. 210, 87-98 (2007).

7. Mills, A. A. et al. p63 is a p53 homologue required for limb and epidermal morphogenesis. Nature 398, 708-713 (1999).

8. Yang, A. et al. p63 is essential for regenerative proliferation in limb, craniofacial and epithelial development. Nature 398, 714-718 (1999).

9. Miller, R. G. \& Phillips, R. A. Separation of cells by velocity sedimentation. J. Cell Physiol. 73, 191-201 (1969)

10. Bellve, A. R. et al. Spermatogenic cells of the prepuberal mouse. Isolation and morphological characterization. J. Cell Biol. 74, 68-85 (1977).

11. Liu, Y. et al. Fractionation of human spermatogenic cells using STA-PUT gravity sedimentation and their miRNA profiling. Sci. Rep. 5, 8084 (2015).

12. Bellve, A. R. Purification, culture, and fractionation of spermatogenic cells. Methods Enzymol. 225, 84-113 (1993).

13. Meistrich, M. L., Bruce, W. R. \& Clermont, Y. Cellular composition of fractions of mouse testis cells following velocity sedimentation separation. Exp. Cell Res. 79 , 213-227 (1973).

14. Romrell, L. J., Bellve, A. R. \& Fawcett, D. W. Separation of mouse spermatogenic cells by sedimentation velocity. A morphological characterization. Dev. Biol. 49, 119-131 (1976).

15. Henkel, R. R. \& Schill, W. B. Sperm preparation for ART. Reprod. Biol. Endocrinol. 1, 108 (2003).

16. Dym, M., Kokkinaki, M. \& He, Z. Spermatogonial stem cells: mouse and human comparisons. Birth Defects Res. Part C, Embryo Today: Rev. 87, 27-34 (2009).

17. Levrero, M. et al. The p53/p63/p73 family of transcription factors: overlapping and distinct functions. J. Cell Sci. 113, 1661-1670 (2000).

18. Marin, M. C. \& Kaelin, W. G. Jr. p63 and p73: old members of a new family. Biochim. Biophys. Acta 1470, M93-M100 (2000).

19. Sheikh, M. S. \& Fornace, A. J. Jr. Role of p53 family members in apoptosis. J. Cell Physiol. 182, 171-181 (2000).

20. Hamer, G., Gademan, I. S., Kal, H. B. \& de Rooij, D. G. Role for c-Abl and p73 in the radiation response of male germ cells. Oncogene 20, 4298-4304 (2001).

21. Inoue, S. et al. TAp73 is required for spermatogenesis and the maintenance of male fertility. Proc. Natl. Acad. Sci. USA 111, 1843-1848 (2014).

22. Kurita, T., Cunha, G. R., Robboy, S. J., Mills, A. A. \& Medina, R. T. Differential expression of p63 isoforms in female reproductive organs. Mech. Dev. 122, 1043-1055 (2005).

23. Suh, E. K. et al. p63 protects the female germ line during meiotic arrest. Nature 444, 624-628 (2006)

24. Livera, G. et al. p63 null mutation protects mouse oocytes from radio-induced apoptosis. Reproduction 135, 3-12 (2008).

25. Nakamuta, N. \& Kobayashi, S. Expression of p63 in the testis of mouse embryos. J. Vet. Med. Sci. 65, 853-856 (2003).

26. Rotter, $\mathrm{V}$. et al. Mice with reduced levels of p53 protein exhibit the testicular giant-cell degenerative syndrome. Proc. Natl. Acad. Sci. USA 90, 9075-9079 (1993).

27. Knudson, C. M., Tung, K. S., Tourtellotte, W. G., Brown, G. A. \& Korsmeyer, S. J Bax-deficient mice with lymphoid hyperplasia and male germ cell death. Science 270, 96-99 (1995).

28. Rodriguez, l., Ody, C., Araki, K., Garcia, I. \& Vassalli, P. An early and massive wave of germinal cell apoptosis is required for the development of functional spermatogenesis. EMBO J. 16, 2262-2270 (1997).

29. Ivell, R. \& Bathgate, R. A. Reproductive biology of the relaxin-like factor (RLF/ INSL3). Biol. Reprod. 67, 699-705 (2002).

30. Ivell, R. \& Einspanier, A. Relaxin peptides are new global players. Trends Endocrinol. Metab. 13, 343-348 (2002). 
31. Hadziselimovic, F. \& Adham, I. Insulin 3-like hormone and its role in epididymo-testicular descent. Int. Braz. J. Urol. 33, 407-411 (2007). discussion 411-403.

32. Sozubir, S. et al. Loss of Insl3: a potential predisposing factor for testicular torsion. J. Urol. 183, 2373-2379 (2010).

33. Sagata, D. et al. The insulin-like factor 3 (INSL3)-receptor (RXFP2) network functions as a germ cell survival/anti-apoptotic factor in boar testes. Endocrinology 156, 1523-1539 (2015).

34. Moreno-Bueno, G. et al. Abnormalities of the APC/beta-catenin pathway in endometrial cancer. Oncogene 21, 7981-7990 (2002).

35. Kato, N., Shibuya, H., Fukase, M., Tamura, G. \& Motoyama, T. Involvement of adenomatous polyposis coli (APC) gene in testicular yolk sac tumor of infants. Hum. Pathol. 37, 48-53 (2006).

36. Aoki, K. \& Taketo, M. M. Adenomatous polyposis coli (APC): a multi-functional tumor suppressor gene. J. Cell Sci. 120, 3327-3335 (2007).

37. Kerr, G. E., Young, J. C., Horvay, K., Abud, H. E. \& Loveland, K. L. Regulated Wnt/ beta-catenin signaling sustains adult spermatogenesis in mice. Biol. Reprod. 90, 3 (2014).

38. Takubo, K. et al. Premeiotic germ cell defect in seminiferous tubules of Atmnull testis. Biochem. Biophys. Res. Commun. 351, 993-998 (2006).

39. Elson, A. et al. Pleiotropic defects in ataxia-telangiectasia protein-deficient mice. Proc. Natl Acad. Sci. USA 93, 13084-13089 (1996).

40. McKinnon, P. J. ATM and ataxia telangiectasia. EMBO Rep. 5, $772-776$ (2004).

41. Shiloh, Y. ATM and related protein kinases: safeguarding genome integrity. Nat. Rev. Cancer 3, 155-168 (2003).

42. Costoya, J. A. et al. Essential role of Plzf in maintenance of spermatogonial stem cells. Nat. Genet. 36, 653-659 (2004).

43. Buaas, F. W. et al. Plzf is required in adult male germ cells for stem cell selfrenewal. Nat. Genet. 36, 647-652 (2004).

44. Lee, K. H. et al. Dazl can bind to dynein motor complex and may play a role in transport of specific mRNAs. EMBO J. 25, 4263-4270 (2006).

45. Haston, K. M., Tung, J. Y. \& Reijo Pera, R. A. Dazl functions in maintenance of pluripotency and genetic and epigenetic programs of differentiation in mouse primordial germ cells in vivo and in vitro. PLOS ONE 4, e5654 (2009).

46. Reynolds, N. et al. Dazl binds in vivo to specific transcripts and can regulate the pre-meiotic translation of Mvh in germ cells. Hum. Mol. Genet. 14 3899-3909 (2005)

47. Lin, Y. M. et al. Expression patterns and transcript concentrations of the autosomal DAZL gene in testes of azoospermic men. Mol. Hum. Reprod. 7, 1015-1022 (2001)

48. Nagafuchi, S. et al. A minute deletion of the $Y$ chromosome in men with azoospermia. J. Urol. 150, 1155-1157 (1993).

49. Nakahori, $Y$. et al The $Y$ chromosome region essential for spermatogenesis. Horm. Res. 46, 20-23 (1996).(Suppl 1).

50. Saxena, R. et al. The DAZ gene cluster on the human $Y$ chromosome arose from an autosomal gene that was transposed, repeatedly amplified and pruned. Nat. Genet. 14, 292-299 (1996).

51. Kumar, S. et al. Sex-specific timing of meiotic initiation is regulated by Cyp26b1 independent of retinoic acid signalling. Nat. Commun. 2, 151 (2011).

52. van Pelt, A. M. et al. Characteristics of A spermatogonia and preleptotene spermatocytes in the vitamin A-deficient rat testis. Biol. Reprod. 53, 570-578 (1995).

53. Vernet, N. et al. Prepubertal testis development relies on retinoic acid but not rexinoid receptors in Sertoli cells. EMBO J. 25, 5816-5825 (2006).

54. Mark, M. et al. STRA8-deficient spermatocytes initiate, but fail to complete, meiosis and undergo premature chromosome condensation. J. Cell Sci. 121 3233-3242 (2008).

55. Dikovskaya, D. et al. The adenomatous polyposis coli protein contributes to normal compaction of mitotic chromatin. PLOS ONE 7, e38102 (2012).

56. Rashid, S. et al. The murine Dnali1 gene encodes a flagellar protein that interacts with the cytoplasmic dynein heavy chain 1. Mol. Reprod. Dev. 73, 784-794 (2006).

57. Jones, R. T. et al. Cross-reactivity of the BRAF VE1 antibody with epitopes in axonemal dyneins leads to staining of cilia. Mod. Pathol. 28, 596-606 (2015).

58. Junco, A., Bhullar, B., Tarnasky, H. A. \& van der Hoorn, F. A. Kinesin light-chain $\mathrm{KLC3}$ expression in testis is restricted to spermatids. Biol. Reprod. 64 1320-1330 (2001)
59. Zhou, D. et al. A novel P53/POMC/Galphas/SASH1 autoregulatory feedback loop activates mutated SASH1 to cause pathologic hyperpigmentation. J. Cell Mol. Med. 21, 802-815 (2017).

60. Reichrath, J., Reichrath, S., Heyne, K., Vogt, T. \& Roemer, K. Tumor suppression in skin and other tissues via cross-talk between vitamin D- and p53-signaling. Front. Physiol. 5, 166 (2014).

61. Chen, L. et al. P53-induced microRNA-107 inhibits proliferation of glioma cells and down-regulates the expression of CDK6 and Notch-2. Neurosci. Lett. 534 327-332 (2013).

62. Wang, Y. et al. Overexpression of SIRT1 promotes high glucose-attenuated corneal epithelial wound healing via p53 regulation of the IGFBP3/IGF-1R/AKT pathway. Invest. Ophthalmol. Vis. Sci. 54, 3806-3814 (2013).

63. Akhter, R., Sanphui, P., Das, H., Saha, P. \& Biswas, S. C. The regulation of p53 up-regulated modulator of apoptosis by JNK/C-Jun pathway in beta-amyloid-induced neuron death. J. Neurochem. 134, 1091-1103 (2015).

64. Azzam, G., Wang, X., Bell, D. \& Murphy, M. E. CSF1 is a novel p53 target gene whose protein product functions in a feed-forward manner to suppress apoptosis and enhance p53-mediated growth arrest. PLOS ONE 8, e74297 (2013).

65. Talukder, K. A. et al. Activation of p53/ATM-dependent DNA damage signaling pathway by shiga toxin in mammalian cells. Microb. Pathog. 52, 311-317 (2012).

66. Marzano, F. et al. The p53 family member p73 modulates the proproliferative role of IGFBP3 in short children born small for gestational age. Mol. Biol. Cell 26, 2733-2741 (2015).

67. Vikhanskaya, F. et al. p73 supports cellular growth through c-Jun-dependent AP-1 transactivation. Nat. Cell Biol. 9, 698-705 (2007).

68. Terrinoni, A. et al. Role of p63 and the Notch pathway in cochlea development and sensorineural deafness. Proc. Natl Acad. Sci. USA 110, 7300-7305 (2013).

69. Barbieri, C. E. et al. IGFBP-3 is a direct target of transcriptional regulation by DeltaNp63alpha in squamous epithelium. Cancer Res. 65, 2314-2320 (2005).

70. Ogawa, E. et al. p63/p51-induced onset of keratinocyte differentiation via the c-Jun $\mathrm{N}$-terminal kinase pathway is counteracted by keratinocyte growth factor. J. Biol. Chem. 283, 34241-34249 (2008).

71. Craig, A. L. et al. DeltaNp63 transcriptionally regulates ATM to control p53 Serine-15 phosphorylation. Mol. Cancer 9, 195 (2010).

72. Wang, J. et al. Symmetrical and asymmetrical division analysis provides evidence for a hierarchy of prostate epithelial cell lineages. Nat. Commun. 5, 4758 (2014).

73. Ru, Y., Zhou, Y. \& Zhang, Y. Transient receptor potential-canonical 3 modulates sperm motility and capacitation-associated protein tyrosine phosphorylation via [Ca2 +]i mobilization. Acta Biochim. Biophys. Sin. 47, 404-413 (2015).

74. Long, J. A. et al. Sperm capacitation and the acrosome reaction are compromised in teratospermic domestic cats. Biol. Reprod. 54, 638-646 (1996).

75. Zhi E. et al. Decreased Expression of KIFC1 in Human Testes with Globozoospermic Defects. Genes 7, 75 (2106).

76. He, Z. et al. Isolation of human male germ-line stem cells using enzymatic digestion and magnetic-activated cell sorting. Methods Mol. Biol. 825, 45-57 (2012).

77. Wang, H. et al. BMP6 regulates proliferation and apoptosis of human sertoli cells via Smad2/3 and Cyclin D1 pathway and DACH1 and TFAP2A activation. Sci. Rep. 7, 45298 (2017).

78. Jiang, H., Lei, R., Ding, S. W. \& Zhu, S. Skewer: a fast and accurate adapte trimmer for next-generation sequencing paired-end reads. BMC Bioinformat. 15, 182 (2014)

79. Trapnell, C., Pachter, L. \& Salzberg, S. L. TopHat: discovering splice junctions with RNA-Seq. Bioinformatics 25, 1105-1111 (2009)

80. Feng, J. et al. GFOLD: a generalized fold change for ranking differentially expressed genes from RNA-seq data. Bioinformatics 28, 2782-2788 (2012).

81. Audic, S. \& Claverie, J. M. The significance of digital gene expression profiles. Genome Res. 7, 986-995 (1997). 